WSRC-STI-2006-00247, Rev. 0

Key Words:

Environment

Remediation

Retention:

Permanent

\title{
Evaluating an Innovative Oxygen Sensor for Remote Subsurface Oxygen Measurements
}

(A Research Study of the Monitored Natural Attenuation/Enhanced Attenuation for Chlorinated Solvents Technology Alternative Project)

\section{October 12, 2006}

Washington Savannah River Company
Savannah River Site
Aiken, SC 29808
$\begin{aligned} & \text { Prepared for the U.S. Department of Energy } \\ & \text { Under Contract Number DEAC09-96- } \\ & \text { SR18500 }\end{aligned}$


WSRC-STI-2006-00247, Rev. 0

\section{DISCLAIMER}

Preparation of this report was coordinated by Washington Savannah River Company (WSRC) for the United States Department of Energy (US DOE) under Contract No. DE-AC09-96SR18500. Extensive effort was made by the authors to assure the accuracy of the contents and interpretation. However, the USDOE nor WSRC, nor any of their employees makes any warranty, expressed or implied, or assumes any legal liability or responsibility for accuracy, completeness, or usefulness, of any information, apparatus, or product or process disclosed herein or represents that its use will not infringe privately owned rights. Reference herein to any specific commercial product, process, or service by trade name, trademark, name, manufacturer or otherwise does not necessarily constitute or imply endorsement, recommendation, or favoring of same by Washington Savannah River Company or by the United States Government or any agency thereof. The views and opinions of the authors expressed herein do not necessarily state or reflect those of the United States Government or any agency thereof.

Printed in the United States of America

Prepared For

U.S. Department of Energy 
WSRC-STI-2006-00247, Rev. 0

October 12, 2006

Page I-iii of I-vii

Key Words:

Environment

Remediation

Retention:

Permanent

\section{Evaluating an Innovative Oxygen Sensor for Remote Subsurface Oxygen Measurements}

(A Research Study of the Monitored Natural Attenuation/Enhanced Attenuation for Chlorinated Solvents Technology Alternative Project)

Contributing Researchers:

Margaret R. Millings, SRNL

Brian D. Riha, SRNL

W. Keith Hyde, SRNL

Introduced by:

Karen Vangelas, SRNL

Brian B. Looney, SRNL

\section{October 12, 2006}

\begin{tabular}{|l|l|}
\hline $\begin{array}{l}\text { Washington Savannah River Company } \\
\text { Savannah River Site } \\
\text { Aiken, SC } 29808\end{array}$ \\
$\begin{array}{l}\text { Prepared for the U.S. Department of Energy } \\
\text { Under Contract Number DEAC09-96- } \\
\text { SR18500 }\end{array}$
\end{tabular}




\section{Executive Summary}

Oxygen is a primary indicator of whether anaerobic reductive dechlorination and similar redox based processes contribute to natural attenuation remedies at chlorinated solvent contaminated sites. Thus, oxygen is a viable indicator parameter for documenting that a system is being sustained in an anaerobic condition. A team of researchers investigated the adaptation of an optical sensor that was developed for oceanographic applications. The optical sensor, because of its design and operating principle, has potential for extended deployment and sensitivity at the low oxygen levels relevant to natural attenuation. The results of the research indicate this tool will be useful for in situ long-term monitoring applications, but that the traditional characterization tools continue to be appropriate for characterization activities.

\section{Introduction}

Page I-iv of I-vii

Over the past three decades, much progress has been made in the remediation of soil and groundwater contaminated by chlorinated solvents. Yet these pervasive contaminants continue to present a significant challenge to the U.S. Department of Energy (DOE), other federal agencies, and other public and private organizations. The physical and chemical properties of chlorinated solvents make it difficult to rapidly reach the low concentrations typically set as regulatory limits. These technical challenges often result in high costs and long remediation time frames. In 2003, the DOE through the Office of Environmental Management funded a science-based technical project that uses the U.S. Environmental Protection Agency's technical protocol (EPA, 1998) and directives (EPA, 1999) on Monitored Natural Attenuation (MNA) as the

foundation on which to introduce supporting concepts and new scientific developments that will support remediation of chlorinated solvents based on natural attenuation processes. This project supports the direction in which many site owners want to move to complete the remediation of their site(s), that being to complete the active treatment portion of the remedial effort and transition into MNA.

The overarching objective of the effort was to examine environmental remedies that are based on natural processes - remedies such as Monitored Natural Attenuation (MNA) or Enhanced Attenuation (EA). The research program did identify several specific opportunities for advances based on: 1) mass balance as the central framework for attenuation based remedies, 2) scientific advancements and achievements during the past ten years, 3) regulatory and policy development and real-world experience using MNA, and 4) exploration of various ideas for integrating attenuation remedies into a systematic set of "combined remedies" for contaminated sites. These opportunities are summarized herein and are addressed in more detail in referenced project documents and journal articles, as well as in the technical and regulatory documents being developed within the ITRC.

Three topic areas were identified to facilitate development during this project. Each of these topic areas, 1) mass balance, 2) enhanced attenuation (EA), and 3) innovative 
WSRC-STI-2006-00247, Rev. 0

October 12, 2006

Page I-v of I-vii

characterization and monitoring, was explored in terms of policy, basic and applied research, and the results integrated into a technical approach. Each of these topics is documented in stand alone reports, WSRC-STI-2006-00082, WSRC-STI-2006-00083, and WSRC-STI-2006-00084, respectively. In brief, the mass balance efforts are examining methods and tools to allow a site to be evaluated in terms of a system where the inputs, or loading, are compared to the attenuation and destruction mechanisms and outputs from the system to assess if a plume is growing, stable or shrinking. A key in the mass balance is accounting for the key attenuation processes in the system and determining their rates. EA is an emerging concept that is recognized as a transition step between traditional treatments and MNA. EA facilitates and enables natural attenuation processes to occur in a sustainable manner to allow transition from the primary treatment to MNA. EA technologies are designed to either boost the level of the natural attenuation processes or decrease the loading of contaminants to the system for a period of time sufficient to allow the remedial goals to be met over the long-term. For characterization and monitoring, a phased approach based on documenting the site specific mass balance was developed. Tools and techniques to support the approach included direct measures of the biological processes and various tools to support cost-effective long-term monitoring of systems where the natural attenuation processes are the main treatment remedies. The effort revealed opportunities for integrating attenuation mechanisms into a systematic set of "combined remedies" for contaminated sites.

An important portion of this project was a suite of 14 research studies that supported the development of the three topic areas. A research study could support one or more of these three topic areas, with one area identified as the primary target. The following report documents the results of the evaluation of applying an oxygen sensor developed for oceanographic needs to subsurface monitoring. This effort was led by Margaret Millings of the Savannah River National Laboratory. This study supports the topic area(s) of characterization and monitoring. The objective of the study was to evaluate whether an optical oxygen sensor developed for oceanographic purposes could be adapted for characterization and monitoring of natural attenuation based remedies. The sensor eliminates the reagents, electrodes and organic membrane in a traditional oxygen sensor and eliminates the need to pump water to the surface as required by wet chemical methods. In previous studies, the sensor was shown to provide reliable and reproducible results when deployed in the ocean for extended timeframes. Thus, the sensor was identified as having significant potential for use in monitoring natural and enhanced attenuation remedies in cases where the redox status of the subsurface environment must be sustained and documented. The study had two sub-objectives:

1) How does this tool compare to traditional oxygen measurement techniques used for subsurface characterization and monitoring?

2) Can the tool be deployed in situ for long-term monitoring applications? 
WSRC-STI-2006-00247, Rev. 0

October 12, 2006

Page I-vi of I-vii

The accurate measurement of dissolved oxygen at the low concentrations $(<1 \mathrm{mg} / \mathrm{L})$ using traditional measuring methods was a topic of discussion among the MNA/EA project's Technical Working Group. This research project was funded as it addressed several of the issues the team had varying opinions on. The study compared traditional measuring methods (colorimetric kits, modified Winkler titrations, membrane

electrochemical sensors) with an optical sensor, as well as investigating the application of this optical sensor for in situ long-term monitoring. The results of the study indicate that the optical sensor has advantages over traditional methods for in situ long-term monitoring applications. For characterization efforts, the researchers recommended continuing the use of the traditional methods, as the optical sensor does not result in more accurate measurements and the initial cost of the sensor may be prohibitive. 
WSRC-STI-2006-00247, Rev. 0

October 12, 2006

\section{References for Introduction}

Page I-vii of I-vii

EPA, 1998. Technical Protocol for Evaluating Natural Attenuation of Chlorinated Solvents in Groundwater, EPA/600/R-98/128. Washington DC. September 1998.

EPA, 1999. Use of Monitored Natural Attenuation at Superfund, RCRA Corrective Action and Underground Storage Tank Sites, OSWER Directive 9200.4-17P. Washington DC. April 21, 1999.

WSRC-STI-2006-00082, 2006. Mass Balance: A Key to Advancing Monitored and Enhanced Attenuation for Chlorinated Solvents. Washington Savannah River Company, Aiken, SC, 29808. June 2006. Available at www.osti.gov.

WSRC-STI-2006-00083, 2006. Enhanced Attenuation: A Reference Guide on Approaches to Increase the Natural Treatment Capacity of a System, Revision 1. Washington Savannah River Company, Aiken, SC, 29808. August 2006. Available at www.osti.gov.

WSRC-STI-2006-00084, 2006. Characterization and Monitoring of Natural Attenuation of Chlorinated Solvents in Ground Water: A Systems Approach, Revision 1. Washington Savannah River Company, Aiken, SC, 29808. August 2006. Available at www.osti.gov. 
United States Department of Energy

Savannah River Site

\section{Evaluating an Innovative Oxygen Sensor for Remote Subsurface Oxygen Measurements}

M. R. Millings

B. D. Riha

W. K. Hyde

WSRC-STI-2006-00247

Revision 0

October 12, 2006

Prepared by:

Washington Savannah River Company LLC

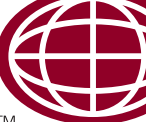
Savannah River Site

Aiken, SC 29808

Prepared for U.S. Department of Energy under Contract No. DE-AC09-96SR18500 


\title{
DISCLAIMER
}

This report was prepared by Washington Savannah River Company LLC (WSRC) for the United States Department of Energy under Contract No. DE-AC09-96SR18500 and is an account of work performed under that contract. Reference herein to any specific commercial product, process or services by trademark, name, manufacturer or otherwise does not necessarily constitute or imply endorsement, recommendation, or favoring of same by WSRC or the United States Government or any agency thereof.

\author{
Printed in the United States of America \\ Prepared for \\ U. S. Department of Energy \\ and \\ Washington Savannah River Company LLC \\ Aiken, South Carolina
}




\section{TABLE OF CONTENTS}

\begin{tabular}{|c|c|}
\hline & INTRODUCTION \\
\hline & Objectives \\
\hline 1.2 & caditional Monitoring Methods... \\
\hline 1.3 & Aanderaa Oxygen Sensor................ \\
\hline 1.4 & ACT Comparative Study... \\
\hline 1.5 & Technical Approach \\
\hline 2.0 & 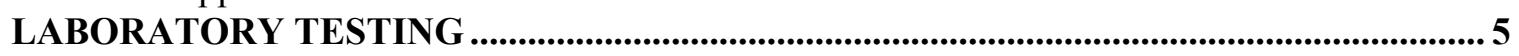 \\
\hline .1 & 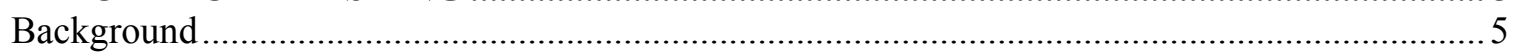 \\
\hline 2.2 & Laboratory Testing Results.... \\
\hline 3.0 & FIELD TESTING \\
\hline & C Area Burning Rubble Pit (CBRP) \\
\hline & P Reactor Area \\
\hline 3.3 & 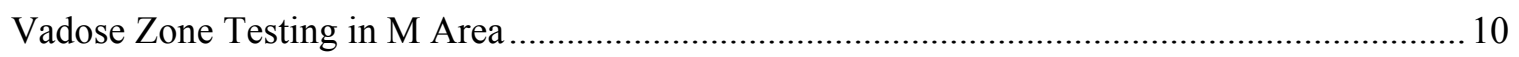 \\
\hline 4.0 & DISCUSSION \\
\hline .1 & 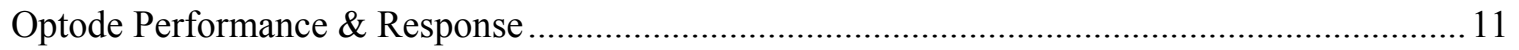 \\
\hline .2 & Fouling \& Degradation ... \\
\hline & Logistics \& Cost .............. \\
\hline & 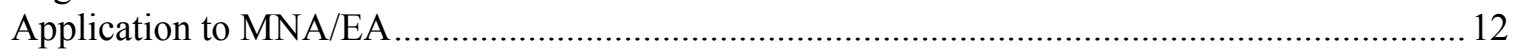 \\
\hline & 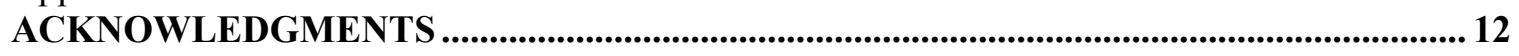 \\
\hline & REFERENCEST, 13 \\
\hline
\end{tabular}

\section{LIST OF FIGURES}

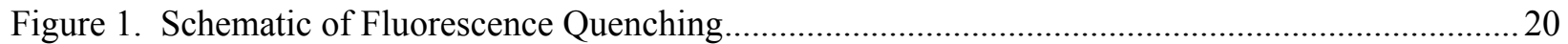

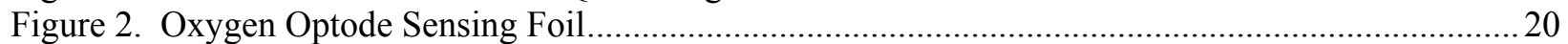

Figure 3. Aanderaa performance at Belleville Lake, MI, ACT Comparative Study ..............................221

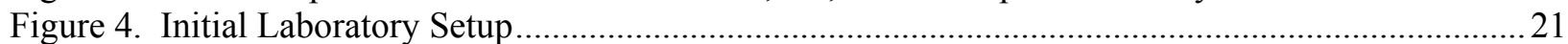

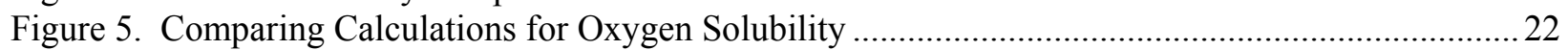

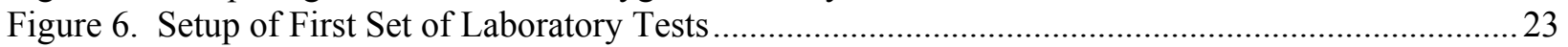

Figure 7. D.O. Results from First Set of Laboratory Testing .............................................................. 24

Figure 8. D.O. Results $(0-3 \mathrm{mg} / \mathrm{L})$ from First Set of Laboratory Testing ............................................. 24

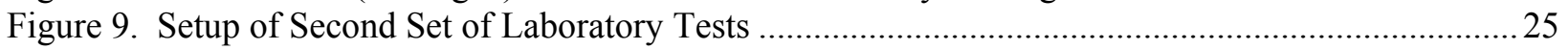

Figure 10. D.O. Results from Second Set of Laboratory Testing .....................................................26

Figure 11. Calibration Data Logging System for CBRP...................................................................2 27

Figure 12. Location of CRP42B in relation to TCE Plume at CBRP ..................................................28

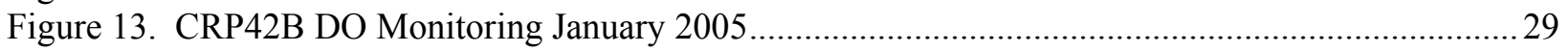

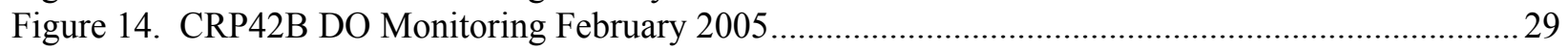

Figure 15. Dissolved Oxygen Concentrations in CRP42B after Redeployment of Optode ...................... 30

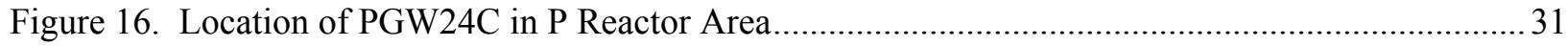

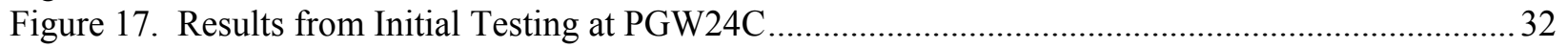

Figure 18. Results of Field Measurement Depth Profile Using YSI in PGW24C ..................................33

Figure 19. Installation of Bladder Pump, Aanderaa Optode, and data logging system at PGW24C ......... 34

Figure 20. Results from Deployment of Optode in PGW24C …........................................................ 35

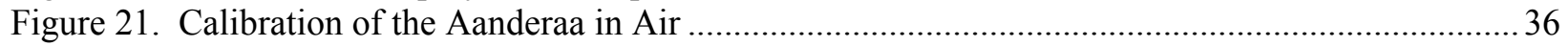

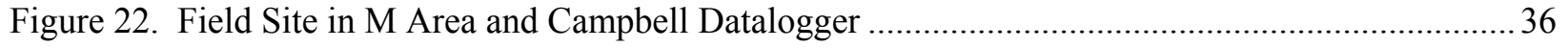




\section{LIST OF TABLES}

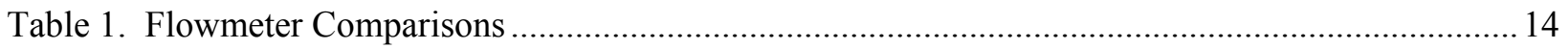

Table 2. Parameters Used for Initial DO Calculation and Calibration................................................... 15

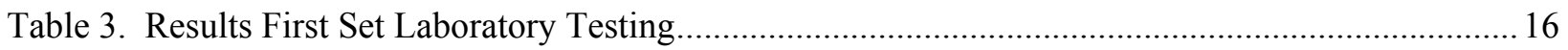

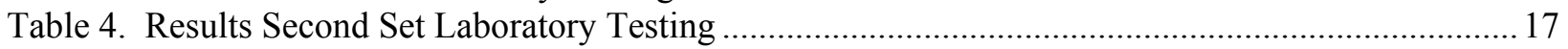

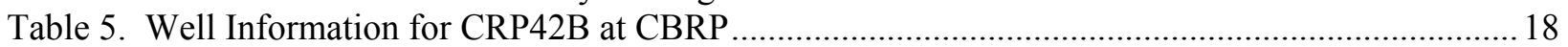

Table 6. Summary D.O., Temperature, Battery Power at CBRP ............................................................ 18

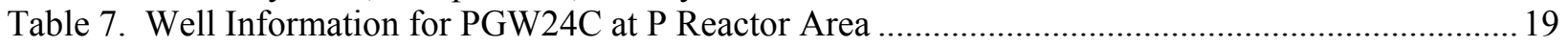

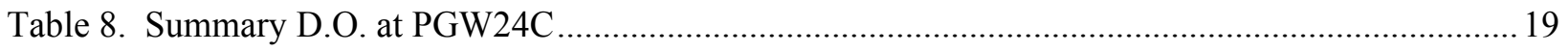




\section{LIST OF ACRONYMS AND ABBREVIATIONS}

\begin{tabular}{|l|l|}
\hline AADI & Aanderaa Data Instruments \\
\hline ACT & Alliance for Coastal Technologies \\
\hline atm & atmosphere \\
\hline bls & below land surface \\
\hline CBRP & C Area Burning Rubble Pit \\
\hline DCE & Dichloroethene \\
\hline D.O. or DO & dissolved oxgyen \\
\hline DOE & Department of Energy \\
\hline ft & feet \\
\hline g & gram(s) \\
\hline hPa & hectopascals \\
\hline LED & light emitting diode \\
\hline m & meters \\
\hline MNA/EA & Monitored Natural Attenuation/Enhanced Attenuation \\
\hline mA & milliampere \\
\hline mg/L & milligrams per liter \\
\hline mL & milliliter \\
\hline PCE & tetrachloroethylene \\
\hline ppm & part per million \\
\hline ppt & pounds per trillion \\
\hline psi & pounds per square inch \\
\hline TCE & trichloroethylene \\
\hline TOC & top of casing \\
\hline TZ & transmissive zone \\
\hline umol/L & micromoles per liter \\
\hline UTRA & Upper Three Runs Aqifer \\
\hline VC & vinyl chloride \\
\hline VOC & volatile organic compound \\
\hline & \\
\hline
\end{tabular}




\subsection{INTRODUCTION}

\section{$1.1 \quad$ Objectives}

The accurate measurement of oxygen concentrations (or partial pressure) in the subsurface is critical to understanding the presence and rate of many natural attenuation mechanisms (White et al, 1990; Odermatt, 1999). Dissolved oxygen levels in groundwater can significantly affect biological activity, which in turn can influence the fate and transport of organic contaminants in the subsurface. For example, tetrachloroethylene (PCE) and trichloroethylene (TCE) are volatile organic compounds that can be readily dechlorinated by microorganisms to dichloroethene (DCE) isomers and vinyl chloride (VC) under anoxic conditions. Only with the right geochemical conditions and microorganisms can this process be completed to form ethene and ethane. In addition to reductive dechlorination, degradation of DCE and VC can also occur in aerobic systems. Monitoring oxygen conditions becomes a key part in understanding whether conditions are favorable (or moving toward favorable) for reductive dechlorination or oxidative degradation to occur. Knowing these conditions can also help to determine the timing and extent of enhancements (e.g., nutrients, microbial culture) needed at a site for complete degradation to occur.

Several studies have examined traditional field and laboratory measurement methods for dissolved oxygen for environmental applications (Rose and Long 1988; White et al, 1990; Wilkin et al, 2001). These methods included electrochemical membrane sensors, colorimetric kits, and Winkler titration based methods. Our primary goal for this study is to evaluate the Aanderaa oceanographic oxygen sensor and its fluorescence based technology as a characterization and long-term monitoring tool for monitored natural attenuation of chlorinated solvents.

This task involves non-baseline, research and development laboratory experiments and field tests for the Department of Energy (DOE) Monitored Natural Attenuation/Enhanced Attenuation (MNA/EA) for Chlorinated Solvents Technology Alternative Project. The goal of the MNA/EA project is to provide scientific and policy support to facilitate the implementation of appropriate passive cleanup and cost effective monitoring strategies. The Technical Working Group for the MNA/EA Project selected studies to fund that supported the technical targets and key concepts they identified as needing development. This oxygen sensor study was one of the fourteen studies selected by the Technical Working Group for the MNA/EA Project.

\subsection{Traditional Monitoring Methods}

Standard methods for measuring dissolved oxygen in groundwater in the field include colorimetric kits, membrane electrochemical sensors, and modified Winkler titrations. Colorimetric kits include the indigo carmine (blue) and rhodazine D (pink) methods. For these methods, color changes are proportional to dissolved oxygen concentrations and are measured either by visual comparisons to kit standards or by using a spectrophotometer. The reactions involved with these kits are not influenced by salinity or hydrogen sulfide $\left(\mathrm{H}_{2} \mathrm{~S}\right)$, however the presence of oxidized metals $\left(\mathrm{Fe}^{+3}, \mathrm{Cr}^{+6}, \mathrm{Cu}^{+2}\right)$ and nitrate have been found to influence dissolved oxygen measurements (White et al, 1990; Wilkin et al, 2001).

Traditional field oxygen sensors operate by measuring a changing electrical current produced by a reaction of the analyte (e.g. oxygen) with a sensing material that catalyzes the reaction. The amount of current is proportional to the rate of oxygen reduction and the amount of oxygen available for the reaction.

Because the sensing material is generally not specific to oxygen, these sensors often use a membrane or barrier to limit sensor exposure to other reactive substances. These sensors are useful for making multiple or continuous dissolved oxygen measurements in the field. They typically involve easy one-point calibrations by measuring the oxygen level in water-saturated air and correcting for barometric pressure, temperature and salinity. Many of these sensors have detection levels of approximately $2 \mathrm{umol} / \mathrm{L}(0.06 \mathrm{mg} / \mathrm{L})$ (White et al, 1990), with an accuracy of approximately $\pm 3 \mathrm{umol} / \mathrm{L}( \pm 0.1 \mathrm{mg} / \mathrm{L})$ and a precision of $\pm 1.5 \mathrm{umol} / \mathrm{L}( \pm 0.05 \mathrm{mg} / \mathrm{L})(\mathrm{APHA}, 1998)$.

The Winkler titration or iodometric test has often been used for calibration or checking of other dissolved oxygen measuring methods. This test is considered the most precise and reliable titration method for dissolved oxygen analysis (APHA, 1998). It involves the oxidation of iodide $\left(\mathrm{I}^{-}\right)$to iodine $\left(\mathrm{I}_{2}\right)$, which is then titrated with thiosulfate 
to quantify the amount of dissolved oxygen. Modified methods have been developed to account for the presence of interferences such as nitrate, ferric iron $\left(\mathrm{Fe}^{+3}\right)$, and turbidity (White et al, 1990). Under field conditions, a detection and precision level of approximately $6 \mathrm{umol} / \mathrm{L}(0.2 \mathrm{mg} / \mathrm{L})$ has been reported for this method (Rose and Long, 1988). In a controlled setting with an experienced analyst, this method has a reported precision of $\pm 1.5 \mathrm{umol} / \mathrm{L}( \pm 0.05$ $\mathrm{mg} / \mathrm{L}$ ) for visual endpoint detection and $\pm 0.15 \mathrm{umol} / \mathrm{L}( \pm 0.005 \mathrm{mg} / \mathrm{L})$ for electrometric endpoint detection (APHA, 1998).

Results from the colorimetric methods are comparable with results from the Winkler titration method. In particular, rhodazine $\mathrm{D}$ was found to have a low detection limit of approximately $0.2 \mathrm{umol} / \mathrm{L}(0.006 \mathrm{mg} / \mathrm{L})$ and showed good agreement with the Winkler titration measurements for low $(<0.1 \mathrm{ppm}$ or $\mathrm{mg} / \mathrm{L}$ ) dissolved oxygen (White et al, 1990; Wilkin et al, 2001). The indigo carmine method showed good agreement with the Winkler titration measurements for dissolved oxygen values above $1 \mathrm{mg} / \mathrm{L}$ (Wilkin et al, 2001).

Neither the Winkler titration method nor the colorimetric kits provide continuous field measurements and both can be affected by improper sampling techniques. In addition, the Winkler titration method can be cumbersome to perform in the field because of the numerous steps, various reagents, and uncontrolled field conditions.

Electrochemical sensors can also be affected by sampling techniques, however measurements can be made in-situ or by using a flow-through cell to minimize contact with the atmosphere.

Many problems associated with the electrochemical sensors involve the membrane. Since electrochemical sensors rely on oxygen diffusing through the membrane, they can be limited by the amount of diffusion. In other words, the rate of oxygen reduction at the electrode surface must be faster than the rate of oxygen diffusing in order to get an accurate reading. Since oxygen is consumed in the reaction, a large enough sample of the analyte fluid must also be provided so that an accurate reading may be made. Many of these sensors use mechanical stirring to maintain a homogenized sample, and circulate oxygen-depleted zones away from the sensor. The requirement for circulation is generally not a problem when there is a large volume of fluid available for sampling. However, it may be an issue in applications where only small volumes are available for sensing, or where there is little fluid circulation. The delicate nature of the membranes can lead to erroneous measurements if the membrane is damaged; an air bubble is trapped beneath the membrane when the membrane is installed; or by "poisoning" effects (fouling) produced by hydrogen sulfide and organic compounds.

Long-term effects on the performance of these electrochemical membrane sensors include consumption of the reactant (e.g., oxidation of the lead anode), and aging or degradation of the barrier (membrane) or electrolyte. These effects can lead to changing response and the need for frequent calibration. As a result of these issues, electrochemical sensors may not be well suited for long term in situ monitoring of dissolved oxygen.

Low oxygen environments are conducive for the biodegradation of chlorinated organics. However, in these environments, electrochemical sensors may encounter problems with adequate circulation/diffusion and the possible presence of hydrogen sulfide. Wilkin et al (2001) found that electrochemical sensors provide only qualitative measurements below $1 \mathrm{mg} / \mathrm{L}$ dissolved oxygen and show slow electrode response.

\subsection{Aanderaa Oxygen Sensor}

The Aanderaa oxygen sensor operates by using the fluorescence characteristics of a platinum porphyrin complex encased in a foil. Figure 1 depicts how a molecule in the foil reacts with and without the oxygen. A molecule of photoluminescent or fluorescent material absorbs energy from light shining on the material (at the proper wavelength) and moves into a higher (and less stable) energy state. The molecule, in re-seeking a more stable and lower energy state, releases energy in the form of a photon (fluorescence or luminescence) and relaxes to the ground state. The intensity of the fluorescence emitted during relaxation of the molecules is the base measurement state. If oxygen molecules contact the fluorescent material while the molecules are in their excited state, the oxygen will absorb the excess energy and allow the normally fluorescent material to return to the ground energy state without releasing a photon. The fluorescent light is therefore quenched to a degree that is dependent on the amount of oxygen present. In the instrument configuration used by Aanderaa Instruments, Inc., the fluorescence layer is 
excited by light from a blue light emitting dioide (LED) and produces longer wavelength luminescence (red light), which is sensed by a photodiode (Figure 2) (Aanderaa Instruments, 2004).

This sensor uses a non-oxygen consumptive, stable and accurate spectral method (fluorescence quenching) and has no moving parts. Temperature is measured automatically by the sensor and dissolved oxygen measurements are internally compensated for temperature. The user must input a general value for salinity and pressure in order for the dissolved oxygen measurements to be compensated for these parameters. The optode is not affected by chloride $\left(\mathrm{Cl}^{-}\right)$, hydrogen sulfide $\left(\mathrm{H}_{2} \mathrm{~S}\right)$, sulfate $\left(\mathrm{SO}_{4}^{-2}\right)$, carbon dioxide $\left(\mathrm{CO}_{2}\right)$, carbon monoxide $(\mathrm{CO})$, ammonia $\left(\mathrm{NH}_{3}\right)$ or $\mathrm{pH}$. Interferences do exist for sulfur dioxide $\left(\mathrm{SO}_{2}\right)$ and chlorine gas $\left(\mathrm{Cl}_{2}\right)$. High concentrations of organic solvents such as acetone and chloroform (methylene chloride) can also damage the foil on the optode.

The design and methodology of the instrument make it a potentially good tool for long-term in-situ applications. Foil life is most affected by bleaching from long term use (blue light shining on the foil) or from exposure to direct sunlight. Laboratory testing has shown that the foil life is typically 1 year at a reading interval of 2 seconds and 5 years at a reading interval of 10 seconds (Aanderaa Instruments, 2004). The foil can also be physically damaged or scratched but typically not from normal use. If a foil has been damaged or bleached, it can be replaced.

The manual recommends one year calibrations, however it is noted that the sensors are stable over much longer periods of time based on field experiences. Calibrations are two-point and require the use of air saturated water (e.g., aquarium pump and water) and a zero oxygen solution (e.g., sodium sulfite, $\mathrm{Na}_{2} \mathrm{SO}_{3}$ ). Calibrations are also needed after replacement of the foil. Calibrations are performed by connecting the sensor to a computer and using the manufacturer's supplied software or by communicating with the sensor via a standard terminal communication program.

The Aanderaa oxygen optode can measure between 0 and 500 umol/L $(16 \mathrm{mg} / \mathrm{L})$. According to the manual, using typical calibration protocols, its resolution or precision is $<1 \mathrm{umol} / \mathrm{L}(<0.03 \mathrm{mg} / \mathrm{L})$ and accuracy is $<8 \mathrm{umol} / \mathrm{L}$ $(<0.26 \mathrm{mg} / \mathrm{L})$. There is no reported minimum detection value (Aanderaa Instruments, 2004). The dynamic range and accuracy of the sensor make it potentially suitable for many applications related to passive and enhanced monitored natural attenuation (e.g. characterization and long-term monitoring in vadose zone or aquifer setting).

The Aanderaa Oxygen Optode has been successfully used for long term oxygen monitoring in ocean waters at depth. Its fluorescence based technology has started becoming more prevalent in environmental monitoring. In-Situ now markets the In-Situ Rugged Dissolved Oxygen sensor (RDO) and Hach currently sells the Hach Low Dissolved Oxygen meter (LDO), both of which are based on fluorescence quenching technology. Because the In-Situ RDO sensor attaches to the Troll 9000 creating a 3-inch diameter probe, it was not a viable sensor for this study in which most monitoring wells are only 2 inches.

\subsection{ACT Comparative Study}

In 2004, the NOAA-funded Alliance for Coastal Technologies (ACT) conducted tests in order to compare recently marketed optical luminescence oxygen sensors with traditional electrochemical sensors for coastal applications (http://www.act-us.info/evaluation_reports.php). The evaluations, which focused on accuracy, precision, instrument drift/calibration life, reliability and operating life, consisted of controlled laboratory tests and field applications in estuarine or shallow ( $<10 \mathrm{~m}$ or $33 \mathrm{ft}$ ) marine environments. Instruments evaluated included optical sensors such the Aanderaa DO Optode 3830/3930/3835 and the In-Situ Rugged Dissolved Oxygen (RDO) sensor, in addition to traditional electrochemical sensors such as the YSI Rapid Pulse Dissolved Oxygen Sensor and the Greenspan Dissolved Oxygen Sensor.

Two of each sensor type was used in the tests - one with a biofouling mechanism provided by the manufacturer and one without the biofouling mechanism. Accuracy and precision evaluations were conducted in the laboratory and consisted of testing the sensors in solution with various temperatures, salinities and dissolved oxygen concentrations. For the accuracy tests, dissolved oxygen concentrations varied between 1 and $18 \mathrm{mg} / \mathrm{L}$. Sensor results were compared with samples analyzed by the Winkler chemical titration method. Instrument drift was evaluated in a 4-week freshwater laboratory test and in 4-week field deployments at seven sites representing a range 
of coastal environments in North America. Results from the only freshwater field location are provided in Figure 3 and show good agreement between the Winkler titration method and the Aanderaa sensor.

Laboratory results showed that the Aanderaa and In-Situ sensors without the biofouling mechanisms and the YSI sensor (with or without the biofouling mechanism) were the most accurate. All of the sensors performed well and within specifications in the precision testing and the laboratory instrument drift tests.

For the field deployments, the Aanderaa, In-Situ, and YSI sensors provided long-term stability except in areas where there was heavy biofouling. The In-Situ sensor experienced some corrosion problems associated with its biofouling mechanism in addition to battery problems. Several of the YSI instruments also experienced problems, which were due to a puncture in the membrane, an obstruction on the membrane and drift in a sonde unit. The performance of the Greenspan sensor varied and was attributed to problems associated with biofouling, the lack of salinity corrections in the calculations, and damaged diffusion rods. The study concluded that the optical luminescence sensor technology (Aanderaa and In-Situ sensors) appeared to be "more accurate, stable and less fouling sensitive" than traditional electrochemical sensors despite problems with the design of their biofouling copper shields.

\subsection{Technical Approach}

Although the Aanderaa Oxygen Optode has been tested extensively in the laboratory and has been used in ocean sensing for several years, it has not yet been tested in groundwater well applications nor has it been directly installed into subsurface materials. The tasks involved in this study were designed to evaluate the Aanderaa Oxygen Optode as a characterization and long-term monitoring tool for monitored natural attenuation. Testing included comparisons between the Aanderaa Optode and standard methods of measuring oxygen (e.g. titration kits, electrochemical sensors, flow-through and diffusion head oxygen sensors) under various environmental conditions to assess the reliability and response of the instrument.

Specific experiments are listed and briefly described below.

1. Laboratory testing with controlled experiments in aqueous low oxygen (suboxic) conditions. This testing was designed to accurately determine the reliability of the Aanderaa Optode in conditions where monitored natural attenuation for chlorinated solvents is favored in addition, to comparing it with standard methods (YSI electrochemical sensor and chemical titration). Low oxygen conditions were carefully produced and controlled by using a gas blend of high purity air and nitrogen.

2. Short-term field testing in aquifer wells. Testing was designed to assess the Aanderaa Optode as a characterization tool by comparing the response of the instrument to standard methods. Scenarios included wells with different oxygen levels and contaminant concentrations. Short-term testing was followed by long-term testing for the chosen field locations.

3. Long-term field testing in aquifer wells. The purpose of this testing was to show the dependability of the instrument as a long term monitoring tool (i.e. whether the foil shows any signs of aging in an aquifer with conditions typical of where monitored natural attenuation might occur). Testing included a small-scale purging experiment to evaluate the long-term use of the sensor for collecting samples representative of aquifer.

4. Short-term field testing in vadose zone wells. Residual vadose zone contamination will usually be linked to groundwater contamination and therefore, conditions in the vadose zone (such as oxygen levels) are important. An instrument that has the ability to measure oxygen levels in both the vadose zone and in aquifers would be a valuable tool for both characterization and long-term monitoring. As part of this study, a short term test of the Aanderaa Optode in a passive well was planned to assess the sensor's ability to detect small scale variations in oxygen related to air flow into and out of the ground. Oxygen levels were also measured using standard instruments to compare with the results from the Aanderaa Optode. It is acknowledged that many reliable gas sensors (e.g. Figaro, Apogee sensors) already exist that could also be valuable monitoring and characterization tools for monitoring air, however many of these sensors are not able to also monitor dissolved oxygen in groundwater. 


\subsection{LABORATORY TESTING}

\subsection{Background}

We designed the laboratory testing to investigate the reliability of the Aanderaa Optode (model 3975) in conditions where monitored natural attenuation for chlorinated solvents is favored. Low oxygen conditions were produced and controlled by using a gas blend of air and nitrogen. In addition, we performed standard field testing methods (YSI electrochemical sensor and CHEMetric colorimetric tests) to compare with measurements from the Aanderaa optode and calculated dissolved oxygen values.

The initial laboratory setup involved a simple sparging system in a glass jar with rotameters to regulate the nitrogen and air (Figure 4). A CHEMetric V-2000 Multi-analyte Photometer was used to perform both the indigo carmine and rhodazine D methods. Electrochemical sensors used included a YSI 600 XLM sonde and a YSI 600 XL sonde, each equipped with a dissolved oxygen probe, temperature probe, internal barometer, and datalogging capabilities. Barometric pressure was verified using a calibrated Druck DPI 605.

We performed calibrations per the manufacturer's directions (Aanderaa Instruments, 2004;YSI Inc, 2002). For the Aanderaa optode, calibrations involved creating an air saturated solution (dissolved oxygen is at $100 \%$ saturation), allowing the optode to equilibrate, and inputting a barometric pressure and salinity into the calibration software. For the second calibration point, $5 \mathrm{~g}$ of sodium sulfite were dissolved in $500 \mathrm{~mL}$ deionized water to produce a zero dissolved oxygen solution. Calibration of the YSI also involved using an air saturated solution, waiting for equilibration and inputting the dissolved oxygen value for the appropriate temperature and pressure. For initial testing, Air Liquide Alphagaz1 cylinder air was used to produce the air sparged solution. The $\mathrm{O}_{2}$ content in this air can vary $20 \pm 1 \%$. For later testing, an aquarium pump was used to generate the air sparged solution as recommended by the Aanderaa manual.

A literature review yielded the following possible methods for calculating dissolved oxygen concentrations:

1. Henry's Law Constant:

$$
\mathrm{p}=\mathrm{Hx}
$$

where $\mathrm{H}$ is the Henry's law constant, $\mathrm{x}$ is the mole fraction of $\mathrm{O}_{2}$ in liquid, and $\mathrm{p}$ is partial pressure of the $\mathrm{O}_{2}$ in gas phase (atm) (Perry and Green, 1984).

2. Weber's mean saturation value for calculating gases at mid-depth in aeration tank systems:

$$
\mathrm{C}_{\mathrm{sM}}=\mathrm{C}_{\mathrm{s}} *\left[\mathrm{P} / 29.4+(0)_{\mathrm{t}} / 42\right]
$$

Where $\mathrm{C}_{\mathrm{sM}}$ is the mean saturation for dissolved $\mathrm{O}_{2}, \mathrm{C}_{\mathrm{s}}$ is the saturation concentration of dissolved $\mathrm{O}_{2}$ corrected for dissolved solids and temperature, $\mathrm{P}$ is the absolute pressure (psi) at the depth at which air is introduced in the tank, and $(0)_{\mathrm{t}}$ is the percent concentration of $\mathrm{O}_{2}$ leaving the tank (Weber, 1972).

3. Oxygen solubility data for fresh and sea water based on work from Whipple and Whipple (1911) and Fox (1909) assuming $20.9 \% \mathrm{O}_{2}$ and total pressure of $760 \mathrm{~mm} \mathrm{Hg}$ (in Metcalf \& Eddy, Inc, 1972).

4. Bunsen coefficients and other formulas to account for barometric pressure, water vapor pressure and depth for calculating the solubility of gases in fresh water as documented by Colt (1984). The Bunsen coefficients were developed by Weiss $(1970,1974)$ and allow for relatively easy computation of the solubility of $\mathrm{O}_{2}$ of an arbitrary composition. The following equation is used to calculate a Bunsen coefficient:

$$
\log _{\mathrm{e}} B_{\mathrm{i}}=\mathrm{A}_{1}+\mathrm{A}_{2}(100 / \mathrm{T})+\mathrm{A}_{3} \log _{\mathrm{e}}(\mathrm{T} / 100)+\mathrm{S}\left[\mathrm{B}_{1}+\mathrm{B}_{2}(\mathrm{~T} / 100)+\mathrm{B}_{3}(\mathrm{~T} / 100)^{2}\right]
$$

where $B_{\mathrm{i}}$ is the Bunsen coefficient (the solubility of $\mathrm{O}_{2}$ at standard temperature and pressure per liter of water when the partial pressure of $\mathrm{O}_{2}$ is equal to $\left.1 \mathrm{~atm}\right)$, $\mathrm{T}$ is the absolute temperature $\left({ }^{\circ} \mathrm{C}+273.15\right), \mathrm{S}$ is salinity (ppt), and the constants are: 


$$
\begin{aligned}
& A_{1}=-58.3877 \\
& A_{2}=85.8079 \\
& A_{3}=23.8439
\end{aligned}
$$

$$
\begin{aligned}
& B_{1}=-0.034892 \\
& B_{2}=0.015568 \\
& B_{3}=-0.0019387
\end{aligned}
$$

The Bunsen coefficient is used in the following equation to determine the solubility of $\mathrm{O}_{2}$ :

$$
\mathrm{C}=1000 * \mathrm{~K}_{\mathrm{i}} * B_{\mathrm{i}} * \mathrm{X}_{\mathrm{i}}^{*}\left(\mathrm{BP}-\mathrm{P}_{\mathrm{H} 2 \mathrm{O}}\right) / 760
$$

where $\mathrm{C}$ is the concentration of dissolved $\mathrm{O}_{2}$ at $100 \%$ saturation $(\mathrm{mg} / \mathrm{L}), \mathrm{K}_{\mathrm{i}}$ is equal to molecular weight/molecular volume of $\mathrm{O}_{2}(1.42903), B_{\mathrm{i}}$ is the Bunsen coefficient, $\mathrm{X}_{\mathrm{i}}$ is the mole fraction of $\mathrm{O}_{2}, \mathrm{BP}$ is the barometric pressure $(\mathrm{mm} \mathrm{Hg})$, and $\mathrm{P}_{\mathrm{H} 2 \mathrm{O}}$ is water vapor pressure $(\mathrm{mm} \mathrm{Hg})$ (Colt, 1984).

5. Garcia and Gordon (1992) examined equations from the literature, including Weiss (1970), for calculating $\mathrm{O}_{2}$ solubility at $1 \mathrm{~atm}$ in pure water and seawater (that is in equilibrium with air) as a function of temperature and salinity. They found discrepancies among formulas particularly at low temperatures $(<$ $10^{\circ} \mathrm{C}$ ) and high salinities and proposed a new fit and constants for calculating $\mathrm{O}_{2}$ solubility in seawater (Garcia and Gordon, 1992). Their equation and constants are provided below and are also referenced in the Aanderaa manual (Aanderaa Instruments, 2004).

$$
\mathrm{Ln}\left(\mathrm{C}_{\mathrm{o}}{ }^{*}\right)=\mathrm{A}_{0}+\mathrm{A}_{1} \mathrm{~T}_{\mathrm{s}}+\mathrm{A}_{2} \mathrm{~T}_{\mathrm{s}}{ }^{2}+\mathrm{A}_{3} \mathrm{~T}_{\mathrm{s}}{ }^{3}+\mathrm{A}_{4} \mathrm{~T}_{\mathrm{s}}{ }^{4}+\mathrm{A}_{5} \mathrm{~T}_{\mathrm{s}}{ }^{5}+\mathrm{S}\left(\mathrm{B}_{0}+\mathrm{B}_{1} \mathrm{~T}_{\mathrm{s}}+\mathrm{B}_{2} \mathrm{~T}_{\mathrm{s}}{ }^{2}+\mathrm{B}_{3} \mathrm{~T}_{\mathrm{s}}{ }^{3}\right)+\mathrm{C}_{\mathrm{o}} \mathrm{S}^{2}
$$

where $\left(\mathrm{C}_{\mathrm{o}}{ }^{*}\right)$ is the solubility of $\mathrm{O}_{2}\left(\mathrm{~cm}^{3} /\right.$ liter $)$ at a specific temperature and total pressure of $1 \mathrm{~atm}, \mathrm{~T}_{\mathrm{s}}$ is scaled temperature $=\ln \left[(298.15-\mathrm{t})(273.15+\mathrm{t})^{-1}\right]$, $\mathrm{t}$ is temperature $\left({ }^{\circ} \mathrm{C}\right), \mathrm{S}$ is salinity, and the constants $\left(\mathrm{cm}^{3} / \mathrm{L}\right)$ are:

$$
\begin{aligned}
& \mathrm{A}_{0}=2.00856 \\
& \mathrm{~A}_{1}=3.22400 \\
& \mathrm{~A}_{2}=3.99063 \\
& \mathrm{~A}_{3}=4.80299 \\
& \mathrm{~A}_{4}=9.78188 \mathrm{e}^{-1}
\end{aligned}
$$

$$
\begin{aligned}
& \mathrm{B}_{0}=-6.24097 \mathrm{e}^{-3} \\
& \mathrm{~B}_{1}=-6.93498 \mathrm{e}^{-3} \\
& \mathrm{~B}_{2}=-6.90358 \mathrm{e}^{-3} \\
& \mathrm{~B}_{3}=-4.29155 \mathrm{e}^{-3} \\
& \mathrm{C}_{\mathrm{o}}=-3.11680 \mathrm{e}^{-7}
\end{aligned}
$$

The various equations were compared assuming $\mathrm{O}_{2}$ air content of $20.9 \%$ and a total pressure of $760 \mathrm{~mm} \mathrm{Hg}$. Results are presented in Figure 5 and show good agreement among Fox (1909) and Whipple and Whipple (1911); Perry (1973); Colt (1984); and Garcia and Gordon (1992) particularly for temperatures between 0 and $30^{\circ} \mathrm{C}$.

For laboratory experiments, we calculated oxygen solubility using the Bunsen coefficients and associated formulas from Colt $(1984)$. Depth of the sparger $\left(\mathrm{P}_{\text {hydro }}\right)$ was added to the overall equation:

$$
\mathrm{C}=1000 * \mathrm{~K}_{\mathrm{i}} * B_{\mathrm{i}} * \mathrm{X}_{\mathrm{i}}^{*}\left(\mathrm{BP}+\mathrm{P}_{\mathrm{hydro}}-\mathrm{P}_{\mathrm{H} 2 \mathrm{O}}\right) / 760
$$

This equation was chosen because of its similarity to Garcia and Gordon (1992), but also because barometric pressure, temperature, water vapor pressure, percent oxygen in the air, and sparger depth could be easily manipulated in calculating solubility.

Initial laboratory experiments yielded measured oxygen concentrations that were considerably different from calculated concentrations. These findings prompted a closer examination of the rotameters. A SKC Personal Sampler Bubble Film Calibrator and a digital Sierra Instrument Inc. flowmeter were used to check the rotameters. As shown by Table 1, the calculated flow rates for the rotameters were significantly less than the measured flow rates using the bubble film calibrator and digital flowmeter. Although exact flows are not necessary for this experiment, we determined that the rotameters did not provide the needed accuracy. For further testing, the rotameters were used only to adjust flow rates for the air and nitrogen; the digital flowmeter was used to measure flow rates. 


\subsection{Laboratory Testing Results}

Results are presented from two laboratory tests. Figure 6 provides diagram of the setup for the first set of testing. It includes the addition of the digital flowmeter for calculating flow rates and an Apogee Oxygen Meter (model O2M) to verify oxygen content in the system air. Table 2 presents background information used to calculate the dissolved oxygen and calibrate the instruments for this first set of tests. Using a barometric pressure of $764 \mathrm{~mm} \mathrm{Hg}$, temperature of $17^{\circ} \mathrm{C}$, and inlet oxygen content of $20.5 \%$ (measured by the Apogee), the calculated oxygen solubility equaled $9.52 \mathrm{mg} / \mathrm{L}$. Calibration of the YSI instruments consisted of inputting $9.52 \mathrm{mg} / \mathrm{L}$ into the instrument software after they had equilibrated in the air sparged solution. Calibrating the Aanderaa to this value proved a little more challenging because salinity and barometric pressure are the only modifiable variables in its software. Back calculations yielded an input barometric pressure of $749.5 \mathrm{~mm} \mathrm{Hg}(999.08 \mathrm{hPa})$ in order to calibrate the Aanderaa to the same value $(9.52 \mathrm{mg} / \mathrm{L})$. Approximately 30 minutes after calibration, all three instruments still showed good agreement in their measurements $(9.43-9.49 \mathrm{mg} / \mathrm{L})$ and were similar to the calculated oxygen solubility for that temperature and pressure $\left(9.42 \mathrm{mg} / \mathrm{L}\right.$, assuming a temperature of $17.3^{\circ} \mathrm{C}$, barometric pressure of $761 \mathrm{~mm} \mathrm{Hg}$ and sparger depth of 1 inch).

Table 3, Figure 7, and Figure 8 show the results from the first set of testing. All three instruments measured approximately the same and agreed well with calculated dissolved oxygen values near saturation and near zero. However, in between these two extremes, the Aanderaa optode typically measured 0.5 to $1 \mathrm{mg} / \mathrm{L}$ less the YSI instruments. Results from the CHEMetrics colorimetric tests (3.59 and $2.28 \mathrm{mg} / \mathrm{L})$ initially were closer to the Aanderaa optode measurements $(3.45$ and $2.11 \mathrm{mg} / \mathrm{L}$ ), however as the dissolved oxygen decreased, the CHEMetrics test results were closer to the YSI measurements.

Several factors could have potentially affected the tests and include:

- Drift in the rotameters - Throughout the testing, small drift was observed in the rotameters balls after they had been positioned at a specific setting.

- Sampling technique for the CHEMetrics tests - Because the water was not flowing, it was difficult to perform the low dissolved oxygen tests using the overflow cup technique recommended in the sampling instructions. Sampling could have easily introduced oxygen into the sample. Dissolved oxygen measurements typically increased when a duplicate sample was collected for the colorimetric test.

- Poor circulation of water/too many instruments in a small space - Observations made at the end of the test suggested that perhaps instrument position relative to the sparger may have made a small difference in readings.

The second set of laboratory testing consisted of a slightly different setup (Figure 9) and a different calibration procedure. For this set of testing, the instruments were calibrated according to manual instructions and general practice. We used an aquarium pump and sodium sulfite solution to calibrate the Aanderaa optode. In the field, we typically calibrate the YSI in water saturated air (per manual instructions) and therefore followed the same protocol for this test. After the initial calibration, both instruments showed similar dissolved oxygen readings of $9.35 \mathrm{mg} / \mathrm{L}$ ( $98.8 \%$ saturation) for the Aanderaa optode and $9.39 \mathrm{mg} / \mathrm{L}$ (98.9\% saturation) for the YSI.

Table 4 and Figure 10 provide the results from the second set of testing. We found good agreement among the YSI sonde, Aanderaa optode, CHEMetrics colorimetric tests, and the calculated oxygen solubility. At low dissolved oxygen levels, the colorimetric test results showed the most difference $(0.76$ and $0.78 \mathrm{mg} / \mathrm{L}$ versus the YSI, which measured $0.53 \mathrm{mg} / \mathrm{L}$, and the Aanderaa, which measured $0.40 \mathrm{mg} / \mathrm{L}$ ). Again, this difference could partly be attributed to sampling technique and the difficulty in collecting a sample without introducing oxygen.

\subsection{FIELD TESTING}

For field testing, each Aanderaa oxygen optode was connected to an Onset Computer Corporation 4-channel Hobo data logger, a 12-volt battery and a solar panel. Wiring was completed by an experienced technical person familiar with the Hobo data loggers, batteries and solar panels used in this study. The Hobo model data logger allows for the measuring of milliampere ( $\mathrm{mA}$ ) and voltage inputs from external sensors such as the Aanderaa. Calibration of the data logging system consisted of placing a calibrated Aanderaa optode into air sparged deionized water and into a zero oxygen solution (sodium sulfite solution). An aquarium pump was used to produce the air sparged solution 
used in calibrating the optode and the data logging system. The stabilized values measured by the data loggers (in $\mathrm{mA}$ ) for dissolved oxygen in the calibration solutions corresponded to $100 \% \mathrm{O}_{2}$ saturation (in the air sparged water) and $0 \% \mathrm{O}_{2}$ saturation (in the Na-sulfite solution). These values were used in converting values measured by the data logging system into dissolved oxygen concentrations. The data loggers also recorded temperature and battery voltage.

\subsection{Area Burning Rubble Pit (CBRP)}

Figure 11 provides the results from the calibration of the data logging system for the Aanderaa optode (serial \#515, "Nemo") deployed at CBRP. The following calibration data were used to convert the Hobo data logger readings into dissolved oxygen values:

- Hobo reading in air saturated solution $\left(\mathrm{O}_{2} 100 \%\right.$ saturated $)$ after stabilization $=13.98 \mathrm{~mA}$

- Hobo reading in sodium sulfite solution $\left(\mathrm{O}_{2} 0 \%\right.$ saturated $)$ after stabilization $=4.06 \mathrm{~mA}$

- Calculated oxygen solubility (accounting for temperature, barometric pressure, water vapor pressure and sparger depth) $=9.31 \mathrm{mg} / \mathrm{L}^{*}$

- $\quad(\mathrm{C}-4.06)^{*} 9.31 *(13.98-4.06)^{-1}$ where $\mathrm{C}=$ channel 1 output in $\mathrm{mA}$

*Note: Dissolved oxygen was also measured in the air sparged solution using a YSI 600 XLM Sonde calibrated in water saturated air. At the beginning of the calibration, the YSI measured $9.26 \mathrm{mg} / \mathrm{L}$ in the air sparged water. At the end of the calibration, the YSI measured $9.32 \mathrm{mg} / \mathrm{L}$ in the air sparged water.

An Aanderaa optode was first deployed in CRP42B, a monitoring well near Twin Lakes at C Area Burning Rubble Pit (Figure 12). Twin Lakes is a wetland region located in the distal part of a trichloroethylene (TCE) plume that emanates from the C Area Burning Rubble Pit. CRP42B is a shallow, PVC well, with a 3-foot screen near the water table (Table 5). We deployed the Aanderaa optode to a depth approximately 10.5 feet below the top of the well casing (TOC). Dissolved oxygen measurements historically have ranged from 1.3 to $4 \mathrm{mg} / \mathrm{L}$, however lower dissolved oxygen measurements $(<1 \mathrm{mg} / \mathrm{L})$ have been observed in shallow groundwater near Twin Lakes (Williams et al, 1999).

After installation, dissolved oxygen initially measured between 1.19 and $1.12 \mathrm{mg} / \mathrm{L}$ on 1/18/05 (Figure 13). Dissolved oxygen values gradually decreased to approximately $0.79 \mathrm{mg} / \mathrm{L}$ by the end of January. The higher initial dissolved oxygen concentrations likely reflected the oxygen introduced during the installation of the sensor in the well. Tree coverage and cloudy days decreased battery life producing several gaps in the data. A second solar panel was connected to the data logging system and provided additional power to the battery.

The Push Pull Testing provided a short term study evaluating the Aanderaa's response to purging. Overall, the Aanderaa showed a quick response to the changing dissolved oxygen conditions during purging and recovery events. In addition, there was relatively good correlation between the Aanderaa and CHEMetrics colorimetric tests (using the CHEMetrics V-2000 photometer and the sampling method suggested by CHEMetrics for low dissolved oxygen samples) (Figure 14).

In particular, we observed an increase in DO concentrations $(2.5-2.8 \mathrm{mg} / \mathrm{L})$ during extensive purging and sampling. Flow rates typically ranged from 200 to $300 \mathrm{~mL} / \mathrm{min}$. During the purge event (which was designed to collect $50 \mathrm{~L}$ water for the Push Pull Testing) and the sampling event for the Push Pull Study, pumping was decreased or stopped to allow the well to recover. Following the recovery period, dissolved oxygen concentrations decreased but not to initial concentrations. Because of the shallow depth of this well, we likely pulled in shallow groundwater with higher dissolved oxygen concentrations during these extensive pumping events. Higher dissolved oxygen concentrations in the shallow groundwater are attributed to the flux of oxygen from the surface and rainfall infiltration.

Subsequent sampling from this well for the Push Pull Testing entailed pumping at very low flow rates to collect 200 $\mathrm{mL}$ of water for analysis. During these events, dissolved oxygen concentrations decreased to approximately 0.45 $\mathrm{mg} / \mathrm{L}$ perhaps drawing in deeper groundwater with low dissolve oxygen or groundwater that was still partially influenced by injectate solution from the Push Pull Testing. Overall, dissolved oxygen measurements remained fairly stable (between 0.53 and $0.75 \mathrm{mg} / \mathrm{L}$ ) during this period. 
In March 2005, we discovered water had infiltrated some of the connections for the data logging system, which caused the optode to stop collecting reliable data. In the initial wiring and set-up, we had not anticipated the frequent retrievals of the sensor from the well (associated with the sampling/purging for other MNA projects at this well cluster). The connections were likely not sturdy enough to support the added stresses nor were they completely water-tight for these activities. Subsequent lab testing with sensor consisted of powering and logging the optode with a laptop computer and revealed that the optode was working properly. In an air sparged solution, it measured $9.33 \mathrm{mg} / \mathrm{L}$ dissolved oxygen ( $98.3 \%$ saturated), which is consistent with the calculated oxygen solubility of 9.36 $\mathrm{mg} / \mathrm{L}$ (for temperature of $18^{\circ} \mathrm{C}$, barometric pressure of $751 \mathrm{mmHg}$, water vapor pressure of $15.48 \mathrm{mmHg}$ and 1-inch sparger depth). In a sodium sulfite solution, the Aanderaa measured $0.15 \mathrm{mg} / \mathrm{L}$. The sensor also maintained a steady reading (between 9.31 and $9.32 \mathrm{mg} / \mathrm{L}$ ) overnight in an air sparged solution. After recalibration of the data logging system, the sensor was redeployed in CRP42B. In contrast to the earlier deployment, the sensor was lowered to approximately 11.25 feet (TOC) so that it was positioned closer to the middle of the screen zone.

During the summer 2005 vegetative cover increased blocking the solar panels and causing some gaps in the data. Moving one of the solar panels into a small clearing approximately 100 feet away from the well and the other solar panel into the wetland restored the needed power for the optode and data logger to function. From May through August 2005, dissolved oxygen levels measured by the optode decreased to near zero with periodic fluctuations (Figure 15). Temperatures slowly increased most likely reflecting the increasing temperatures in the wetland during the summer months. From September 2005 through Janurary 2006, dissolved oxygen levels rose but still remained below $2 \mathrm{mg} / \mathrm{L}$ and temperatures slowly decreased. The periodic fluctuations in dissolved oxygen observed in CRP42B may have been related to the shallowness and short screen zone of this well along with its propensity for pumping dry. Rainfall, sampling of the well for regulatory purposes, and sampling/purging in the adjacent shallow well (CRP42A) for other MNA studies could likely have affected dissolved oxygen concentrations measured in the CRP42B. Table 6 provides a summary of dissolved oxygen concentrations measured by the Aanderaa optode in CRP42B.

\subsection{P Reactor Area}

As part of the testing of the Aanderaa oxygen sensor and to aid SRS Soil and Groundwater Closure Projects in their characterization efforts, we deployed the second Aanderaa oxygen sensor (serial \# 461, "Tethys") in PGW24C, a relatively new monitoring well in P Reactor Area (Figure 16). PGW24C is 100-foot, PVC well, with a 10-foot screen (Table 7). During 2004 dissolved oxygen concentrations in this well varied from 3 to $1.8 \mathrm{mg} / \mathrm{L}$ based on traditional sampling and analysis techniques.

Initial testing involved pumping the well with the dedicated pump (the traditional sampling method for this well) and comparing readings measured by the Aanderaa, a YSI, and a CHEMetrics V-2000 photometer/test kit. A simple flow-through cell was designed and made for the Aanderaa so that both the YSI and the Aanderaa could be run inline off of the monitoring well's sample port. The simplistic flow-through cell was not clear or transparent, which was a drawback since it was difficult to determine whether there was entrapped air in the cell. However, care was taken in the design and use to minimize the occurrence of entrapped air. For this initial testing, datalogging and power was provided by a laptop computer for the Aanderaa sensor. The Aanderaa optode was calibrated in the lab prior to the testing and the YSI was calibrated in the field.

Measurements from the Aanderaa ranged from 0.29 to about $1.0 \mathrm{mg} / \mathrm{L}$ depending on pumping conditions (Figure 17). The YSI consistently measured higher than the Aanderaa (generally 0.3 to $0.5 \mathrm{mg} / \mathrm{L}$ higher) regardless of which instrument was first in-line from the sample port. The CHEMetrics test kits and V-2000 photometer often had measurements in between the two instruments. The CHEMetrics test kits were collected at the end of the sample line (after the Aanderaa and YSI flow-through cells) using an overflow cup and the CHEMetrics sample procedure described for low dissolved oxygen samples. Two of the CHEMetrics samples with higher dissolved oxygen readings may have been removed from the sample cup too quickly and more care was taken in collecting the last two samples. As expected, the dissolved oxygen concentration was observed to increase with the YSI and Aanderaa as the pumping rate was increased. An increase in D.O. from sampling effects (e.g., purging) is important to note. In-situ monitoring would remove potential biases in D.O. concentrations produced from sampling. 
Further testing in PGW24C involved removing the dedicated pump, performing a depth profile using the YSI to measure field parameters, and installation of a Geotech bladder pump (GEO1.66SS18) and the Aanderaa optode. Results from the depth profile indicate that the well is likely grout contaminated; however this well still provided an opportunity for evaluating the Aanderaa optode. In the screen zone, the YSI measured pH levels between 11 and 12 and dissolved oxygen as low as $0.04 \mathrm{mg} / \mathrm{L}$ (Figure 18).

After the depth profile was completed, we installed the bladder pump at a depth of approximately of $106.5 \mathrm{ft}$ (TOC) and the Aanderaa optode at an approximate depth of $104.5 \mathrm{ft}$ (TOC) (Figure 19). The bladder pump and oxygen sensor could not be placed side-by-side because together their diameters would have been greater than the diameter of the monitoring well ( 2 inches). The Aanderaa optode at PGW24C recorded dissolved oxygen measurements from May 2005 through January 2006.

The following calibration data were used to convert the Hobo data logger readings into dissolved oxygen values:

- Hobo reading in air saturated solution $\left(\mathrm{O}_{2} 100 \%\right.$ saturated $)$ after stabilization $=13.19 \mathrm{~mA}$

- Hobo reading in sodium sulfite solution $\left(\mathrm{O}_{2} 0 \%\right.$ saturated $)$ after stabilization $=4.06 \mathrm{~mA}$

- Calculated oxygen solubility (accounting for temperature, barometric pressure, water vapor pressure and sparger depth) $=9.13 \mathrm{mg} / \mathrm{L}^{*}$

- $\quad(\mathrm{C}-4.06) * 9.13 *(13.19-4 . .06)^{-1}$ where $\mathrm{C}=$ channel 1 output in $\mathrm{mA}$

After deployment, the Aanderaa oxygen measurements steadily decreased, fluctuating between 0 and $0.07 \mathrm{mg} / \mathrm{L}$ (Figure 20, Table 8). Although results from the pumping test showed dissolved oxygen concentrations between 0.29 and $1.0 \mathrm{mg} / \mathrm{L}$, the in-situ measurements by the Aanderaa are consistent with the dissolved oxygen concentrations measured during the depth profiling by the YSI $(0.04 \mathrm{mg} / \mathrm{L})$. The higher dissolved oxygen concentrations observed during the pumping test may be attributed to sampling effects associated with the dedicated pump, flow rates, equipment, and analysis procedure as well as the extraction of "fresh" groundwater into the well. It is also important to note that the fluctuations in the Aanderaa measurements between 0 and $0.07 \mathrm{mg} / \mathrm{L}$ reflect the resolution of the data logger output, not the Aanderaa measurements.

During the long-term monitoring in this well, spurious data points were found particularly associated with temperature data. The observed spikes seemed to coincide with downloading events of the datalogger. The temperature spikes did not appear to affect the measured dissolved oxygen concentrations and were therefore considered to be associated with the datalogger and related connections.

\subsection{Vadose Zone Testing in $M$ Area}

Following the long-term studies of the sensors in the monitoring wells, each optode was deployed in the shallow vadose zone in order to assess the functionality of this technology in monitoring oxygen concentrations during a small-scale remediation study. Since residual vadose zone contamination will be linked to groundwater contamination, conditions in the vadose zone (such as oxygen levels) are important. An instrument that has the ability to measure oxygen levels in both the vadose zone and aquifer conditions would be a valuable tool for both characterization and long-term monitoring.

At the study site in M Area, VOC's are present in a shallow (30-foot) clay-rich zone. In 2005, this area was the site of a fracturing demonstration in which water and sand were pumped into the subsurface in order to fracture the clay. In 2006, soybean oil was injected into the subsurface for further study. The sensors were deployed prior to the soybean oil injection to determine background oxygen conditions with the intention of using the sensors throughout the study for monitoring oxygen levels in the shallow clay-rich zone.

Prior to deployment, a small flow-through cell was created to calibrate the Aanderaa oxygen sensor in air. Nitrogen was used to create a $0 \%$ oxygen environment and saturated ambient air was used for the $100 \%$ oxygen environment (in order to simulate $100 \%$ humidity expected in the well). Figure 21 shows the results from the calibration.

For this test, the sensor was deployed in a shallow, 25 -foot well with a short screen ( 5 feet). The well was designed specifically for the sensors and is closed to the surface in order to prevent mixing with atmospheric air. The sensors 
were connected to a Campbell datalogger (Figure 22). The sensors initially operated correctly, but after deployment, the datalogger stopped receiving a reliable signal from either of the sensors. After retrieving the sensors from the field, the sensors appeared to work satisfactorily on digital output; however they were not sending a reliable signal on analog output. Inspection by the manufacturer showed that for both of the sensors the digital to analog converter was cross-polarized, which damaged the sensor chip.

\subsection{DISCUSSION}

The purpose of our study has been to evaluate the Aanderaa optode and its fluorescence based technology for use in characterization and long-term monitoring as related to passive and enhanced monitored natural attenuation. In particular, we were interested in the response of the optode compared to traditional field methods for measuring dissolved oxygen (e.g. YSI electrochemical sensor, CHEMetrics test kits) in groundwater wells in addition to assessing its functionality in monitoring oxygen in vadose zone wells.

\subsection{Optode Performance \& Response}

In aquifer conditions:

In laboratory and field testing, the Aanderaa optode showed relatively good agreement with YSI measurements, CHEMetrics test kit results and calculated dissolved oxygen concentrations. The most variation $(0.5$ to $1.0 \mathrm{mg} / \mathrm{L})$ between the YSI and Aanderaa sensors was observed during the first set of laboratory testing; however setup and calibration procedures may have affected the test results. We did note that the Aanderaa optode typically measured lower dissolved oxygen concentrations than the YSI or the CHEMetrics test kits.

The Aanderaa optodes demonstrated quick response to changing conditions in lab and field tests. In the long-term field tests, we observed a stable optode response even in the high pH conditions in PGW24C. The optode in CRP42B showed good response to changing conditions (temperature and dissolved oxygen concentrations) throughout the summer and winter months.

\section{In Vadose Zone:}

This study was unable to evaluate to document the use of the fluorescence based technology for monitoring oxygen levels in the vadose zone. Although the calibration and initial set-up of the optodes in the vadose zone well was successful, further testing would be required to show their response to changing conditions and reliability. Further study would be needed in this area.

\subsection{Fouling \& Degradation}

No degradation of the foil, mineral precipitation, or biological activity was observed on the optode foils during these studies. However, it should be noted that the experimental testing and subsurface field deployments in this evaluation primarily occurred in oligotrophic environments that have relatively low amounts of microorganisms and dissolved organic carbon. Testing of the optode's long-term monitoring capability in the presence of a diverse and thriving microbiological community would further demonstrate the usefulness of this technology at sites undergoing biostimulation and/or bioaugmentation. Low dissolved oxygen concentrations are typically needed for relatively long periods of time at sites undergoing biostimulation and/or bioaugmentation and therefore a sensor

\subsection{Logistics \& Cost}

Aanderaa Instruments (now part of AADI or Aanderaa Data Instruments) and In-Situ Inc. provide oxygen sensors using the fluorescence based technology. With a 1 1/2-inch diameter, the Aanderaa sensor is better suited to 2-inch monitoring wells than the current In-Situ RDO (Rugged DO) sensor. The In-Situ RDO, which requires the use of the Troll 9000 and 9500 series, measures more than 2-inches in diameter when attached to the Troll.

The initial cost of the instruments used in this evaluation was more than most electrochemical sensors; however there are now alternatives to the titanium housing offered by both Aanderaa and In Situ, Inc. that would make the sensors less expensive. The optode is easy to calibrate using an aquarium pump, a sodium sulfite solution, the Aanderaa supplied software and a laptop computer. Little maintenance has been required on the optodes. Most 
equipment problems during the field studies did not involve the optodes but were related to an increase in vegetative cover (blocking the solar panels), connections that were not sturdy enough or completely water-tight, and operator error.

The Aanderaa oxygen optode is more advantageous than the colorimetric test kits for continuous monitoring or frequent field measurements of dissolved oxygen. Compared to the electrochemical membrane sensors, the Aanderaa optode appears to provide similar accuracy and precision. However, the optodes are more field resilient with fewer chemical and membrane issues. Although the electrochemical sensors such as the YSI offer an easy calibration in the field, the Aanderaa optodes require less calibration. With little maintenance or calibration required, the Aanderaa optode is well suited for in-situ monitoring of dissolved oxygen. In-situ monitoring can eliminate biases in dissolved oxygen measurements due to sampling effects as observed during our field studies.

\subsection{Application to MNA/EA}

This sensor technology would be a valuable tool for sites in which oxygen is a key parameter to monitor to support MNA/EA. Monitoring oxygen is important in order to know whether conditions are favorable or are moving toward favorable for reductive dechlorination or oxidative degradation to occur. Knowing these conditions can also help to determine the timing and extent of enhancements (e.g., nutrients, microbial culture) needed at a site for degradation to occur. Furthermore, at a site undergoing biostimulation and/or bioaugmentation (i.e. EA) where a sufficient source of an electron donor must be maintained, measurements of dissolved oxygen can provide a metric to monitor plume stability. In this scenario, the effectiveness of the EA would be based on maintaining a dissolved oxygen concentration below a pre-determined threshold. This setup would allow for infrequent measurements of primary and daughter contaminants making for a more cost-effective cleanup.

\subsection{ACKNOWLEDGMENTS}

This document is a product of the Monitored Natural Attenuation/Enhanced Attenuation for Chlorinated Solvents Technology Alternative Project. The document was sponsored by the U.S. Department of Energy (DOE) Office of Cleanup Technologies and administered by the U.S. Department of Energy Savannah River (SR) Operations Office (Contract No. DE-AC09-96SR18500). We appreciate the guidance and support of Claire H. Sink of DOE Headquarters and Karen M. Adams of DOE SR. The Savannah River National Laboratory provided technical direction for this project, as well as daily operations and management. We acknowledge the participation and collaboration of other federal agencies, notably, the U.S. Geological Survey (USGS) and the U.S. Environmental Protection Agency (EPA). 


\subsection{REFERENCES}

ALPHA. 1998. Standard Methods for the Examination of Water and Wasterwater. $20^{\text {th }}$ Edition. American Public Health Association, Washington, D. C.

Aanderaa Instruments. 2004. TD218 Operating Manual: Oxygen Optode 3830, 3930 and 3975. Aanderaa Instruments AS, Bergen, Norway. 69p.

Colt, J. 1984. Computation of Dissolved Gas Concentrations in Water as Functions of Temperature, Salinity, and Pressure. America Fisheries Society Special Publication 14, Bethesda, Maryland. 154p.

Fox, C. J. J. 1909. On the Coefficients of Absorption of Nitrogen and Oxygen in Distilled Water and Sea Water and Atmospheric Carbonic Acid in Sea Water. Transactions of the Faraday Society, v.5, p. 68-86.

Garcia, H. and L. I. Gordon. 1992. Oxygen Solubility in Seawater: Better Fitting Equations. Limnology and Oceanography, v.37, n.6, p.1307-1312.

Metcalf \& Eddy, Inc. 1972. Wastewater Engineering: Collection, Treatment, Disposal. Metcalf \& Eddy, Inc. McGraw-Hill, New York. 782p.

Odermatt, J. R. 1999. Remdiation by Natural Attenuation. Ground Water Monitoring and Remediation, v.19, n.3, p.58-60.

Perry, R. H. and D. W. Green. 1984. Perry's Chemical Engineers' Handbook. $6^{\text {th }}$ Edition. McGraw-Hill, New York.

Rose, S. and A. Long. 1988. Monitoring Dissolved Oxygen in Ground Water: Some Basic Considerations. Ground Water Monitoring Review, v.8, p.93-97.

Weber, W. J. Jr. 1972. Physiochemical Processes for Water Quality Control. Wiley-Interscience, New York. $640 \mathrm{p}$.

Whipple, G. C. and Whipple, M. C. 1911. Solublity of Oxygen in Sea Water. Journal of the American Chemical Society, v.33, n.3, p.362-365.

White, A. F., M. L. Peterson, and R. D. Solbau. 1990. Measurement and Interpretation of Low Levels of Dissolved Oxygen in Ground Water. Ground Water, v.28, n.4, p.584-590.

Wilkin, R. T., M. S. McNeil, C. J. Adair, and J. T. Wilson. 2001. Field Measurement of Dissolved Oxygen: A Comparison of Methods. Ground Water Monitoring and Remediation, v.21, n.4, p.124-132.

Williams, J. B., H. Coleman, N. Baldwin, R. Morgan, and T. Shuler. 1999. Evaluation of Monitored Natural Attenuation Conditions Along Waste Plume Outcrops at CMP Pits and CBRP Sites at SRS Summary Report. SCUREF Cooperative Project \#131. 
Table 1. Flowmeter Comparisons

\begin{tabular}{|c|c|c|c|c|c|}
\hline $\begin{array}{c}\text { Air line } \\
\begin{array}{l}\text { Cole Parmer Rotameter } \\
\text { model N032-15 }\end{array} \\
\text { calculated flow } \mathrm{mL} / \mathrm{min}\end{array}$ & $\begin{array}{c}\text { Nitrogen line } \\
\text { Cole Parmer Rotameter } \\
\text { model N062-01 } \\
\text { calculated flow } \mathrm{mL} / \mathrm{min}\end{array}$ & $\begin{array}{c}\text { Sierra Instrument Inc } \\
\text { Gas Flowmeter model } \\
\text { 822-1 (serial\# 19342) } \\
\text { flowmeter reading } \\
\mathrm{mL} / \mathrm{min}\end{array}$ & $\begin{array}{c}\text { secs to travel } \\
\text { from } 0 \text { to } 100 \mathrm{~mL}\end{array}$ & $\operatorname{avg~secs}$ & $\mathrm{mL} / \mathrm{min}$ \\
\hline \multirow[t]{4}{*}{93.2} & -- & 180 & 32 & 32.88 & 182.51 \\
\hline & & & 33 & & \\
\hline & & & 33.5 & & \\
\hline & & & 33 & & \\
\hline \multirow[t]{5}{*}{60.5} & -- & 130 & 47.5 & 48.30 & 124.22 \\
\hline & & & 50 & & \\
\hline & & & 47.5 & & \\
\hline & & & 47.5 & & \\
\hline & & & 49 & & \\
\hline \multirow[t]{4}{*}{16.5} & -- & 40 & 152 & 153.75 & 39.02 \\
\hline & & & 150.5 & & \\
\hline & & & 156 & & \\
\hline & & & 156.5 & & \\
\hline \multirow[t]{4}{*}{--} & 881.6 & 1250 & 6 & 5.34 & 1122.81 \\
\hline & & & 5 & & \\
\hline & & & 5.25 & & \\
\hline & & & 5.125 & & \\
\hline \multirow[t]{4}{*}{--} & 656.3 & 1000 & 6.25 & 6.38 & 941.18 \\
\hline & & & 6.25 & & \\
\hline & & & 6.5 & & \\
\hline & & & 6.5 & & \\
\hline \multirow[t]{4}{*}{--} & 401.9 & 715 & 9 & 9.00 & 666.67 \\
\hline & & & 9.25 & & \\
\hline & & & 9 & & \\
\hline & & & 8.75 & & \\
\hline \multirow[t]{4}{*}{--} & 213.6 & 450 & 13.75 & 13.56 & 442.40 \\
\hline & & & 13.5 & & \\
\hline & & & 13.5 & & \\
\hline & & & 13.5 & & \\
\hline \multirow[t]{4}{*}{16.5} & 213.6 & 490 & 12.25 & 12.31 & 487.31 \\
\hline & & & 12.5 & & \\
\hline & & & 12.25 & & \\
\hline & & & 12.25 & & \\
\hline \multirow[t]{4}{*}{16.5} & 401.9 & 755 & 8 & 8.13 & 738.46 \\
\hline & & & 8 & & \\
\hline & & & 8.25 & & \\
\hline & & & 8.25 & & \\
\hline \multirow[t]{4}{*}{16.5} & 656.3 & 1050 & 5.5 & 5.88 & 1021.28 \\
\hline & & & 6 & & \\
\hline & & & 6 & & \\
\hline & & & 6 & & \\
\hline \multirow[t]{4}{*}{16.5} & 881.6 & 1290 & 5 & 5.00 & 1200.00 \\
\hline & & & 5 & & \\
\hline & & & 5 & & \\
\hline & & & 5 & & \\
\hline \multirow[t]{4}{*}{93.2} & 881.6 & 1430 & 4.5 & 4.50 & 1333.33 \\
\hline & & & 4.5 & & \\
\hline & & & 4.5 & & \\
\hline & & & 4.5 & & \\
\hline
\end{tabular}


Table 2. Parameters Used for Initial DO Calculation and Calibration

\begin{tabular}{|l|c|c|}
\hline \multicolumn{3}{|c|}{ First Set Laboratory Testing } \\
\hline \multicolumn{1}{|c|}{ Instrument } & Temperature $\left({ }^{\circ} \mathrm{C}\right)$ & $\begin{array}{c}\text { Barometric Pressure } \\
(\mathrm{mm} \mathrm{Hg})\end{array}$ \\
\hline Aanderaa (serial\# 461, "Tethys") & 16.92 & $\mathrm{n} / \mathrm{a}$ \\
\hline YSI 600 XLM Sonde & 16.85 & 763.3 \\
\hline YSI 600 XL-B-O Sonde & 16.9 & 762.2 \\
\hline verification instrument $^{2}$ & 17.1 & 764.8 \\
\hline
\end{tabular}

${ }^{1}$ Began sparging with air at 7:50am; parameters measured at 9:25am; finished with instrument calibration $\sim 10: 15 \mathrm{am}$

${ }^{2}$ Temperature verified with calibrated thermometer and barometric pressure measured using calibrated Druck DPI 605 
Table 3. Results First Set Laboratory Testing

\begin{tabular}{|c|c|c|c|c|c|c|c|c|c|c|c|c|}
\hline & Time & $\begin{array}{c}\text { Aanderaa } \\
\text { ("Tethys") }\end{array}$ & $\begin{array}{c}\text { YSI 600 XLM } \\
\text { Sonde }\end{array}$ & $\begin{array}{c}\text { YSI 600 XL } \\
\text { Sonde }\end{array}$ & $\begin{array}{c}\text { Rotameter } \\
\text { Air Setting }\end{array}$ & $\begin{array}{l}\text { Rotameter } \\
\text { N2 Setting }\end{array}$ & $\begin{array}{c}\text { Air Flow } \\
\text { Rate }^{2} \\
(\mathrm{~mL} / \mathrm{min})\end{array}$ & $\begin{array}{c}\text { N2 Flow } \\
\text { Rate }^{2} \\
(\mathrm{~mL} / \mathrm{min})\end{array}$ & $\begin{array}{l}\text { Calculated Inlet } \\
\text { Air O2\% by } \\
\text { volume (based on } \\
\text { flow rates) }\end{array}$ & $\begin{array}{c}\text { Calculated O2 } \\
\text { Solubility }^{1} \\
(\text { Colt, 1984) }\end{array}$ & $\begin{array}{c}\text { Apogee inlet } \\
\text { air } \% \mathrm{O}_{2} \\
\text { saturation }\end{array}$ & $\begin{array}{c}\text { Calculated } \\
\text { inlet } O 2 \% \\
\text { based on } \\
\text { Apogee } \\
(\% * 0.209)\end{array}$ \\
\hline Temperature $\left({ }^{\circ} \mathrm{C}\right)$ & \multirow{4}{*}{ 11:00 } & 17.36 & 17.28 & 17.33 & \multirow{4}{*}{65} & \multirow{4}{*}{0} & \multirow{4}{*}{180} & \multirow{4}{*}{0} & \multirow{4}{*}{$20.50 \%$} & \multirow{4}{*}{$\begin{array}{c}9.42 \mathrm{mg} / \mathrm{L} \\
(\mathrm{T}=17.3 ; \\
\mathrm{BP}=761)\end{array}$} & \multirow{4}{*}{98} & \multirow{4}{*}{$20.48 \%$} \\
\hline \% Saturation & & $98.50 \%$ & $98.80 \%$ & $98.70 \%$ & & & & & & & & \\
\hline Dissolved Oxygen (mg/L) & & 9.43 & 9.49 & 9.48 & & & & & & & & \\
\hline Barometric Pressure $(\mathrm{mm} \mathrm{Hg})$ & & $\mathrm{n} / \mathrm{a}$ & 762.7 & 761.8 & & & & & & & & \\
\hline Temperature $\left({ }^{\circ} \mathrm{C}\right)$ & \multirow{4}{*}{$13: 33$} & 17.28 & 17.22 & 17.26 & \multirow{4}{*}{65} & \multirow{4}{*}{10} & \multirow{4}{*}{180} & \multirow{4}{*}{240} & \multirow{4}{*}{$8.79 \%$} & \multirow{4}{*}{$\begin{array}{l}4.03 \mathrm{mg} / \mathrm{L} \\
(\mathrm{T}=17.4 ; \\
\mathrm{BP}=761)\end{array}$} & \multirow{4}{*}{42} & \multirow{4}{*}{$8.78 \%$} \\
\hline \% Saturation & & $36 \%$ & $45 \%$ & $45.40 \%$ & & & & & & & & \\
\hline Dissolved Oxygen (mg/L) & & 3.45 & 4.33 & 4.36 & & & & & & & & \\
\hline Barometric Pressure (mm Hg) & & $\mathrm{n} / \mathrm{a}$ & 760.9 & 760 & & & & & & & & \\
\hline Temperature $\left({ }^{\circ} \mathrm{C}\right)$ & \multirow{4}{*}{$14: 39$} & 17.18 & 17.11 & 17.16 & \multirow{4}{*}{65} & \multirow{4}{*}{45} & \multirow{4}{*}{180} & \multirow{4}{*}{490} & \multirow{4}{*}{$5.51 \%$} & \multirow{4}{*}{$\begin{array}{c}2.54 \mathrm{mg} / \mathrm{L} \\
(\mathrm{T}=17.1 ; \\
\mathrm{BP}=761)\end{array}$} & \multirow{4}{*}{27} & \\
\hline$\%$ Saturation & & $21.90 \%$ & $30 \%$ & $30.40 \%$ & & & & & & & & 5640 \\
\hline Dissolved Oxygen (mg/L) & & 2.1 & 2.9 & 2.93 & & & & & & & & $5.04 \%$ \\
\hline Barometric Pressure $(\mathrm{mm} \mathrm{Hg})$ & & $\mathrm{n} / \mathrm{a}$ & 760.6 & 759.7 & & & & & & & & \\
\hline Temperature $\left({ }^{\circ} \mathbf{C}\right)$ & & 17.01 & 16.94 & 16.98 & & & & & & & & \\
\hline \% Saturation & 15.02 & $16.52 \%$ & $24.50 \%$ & $24.60 \%$ & 65 & 80 & 180 & 700 & 100 & $1.94 \mathrm{mg} / \mathrm{L}$ & 0 & 4180 \\
\hline Dissolved Oxygen (mg/L) & 15.22 & 1.59 & 2.38 & 2.38 & OS & ov & 100 & 100 & $4.11 \%$ & $\mathrm{BP}=761)$ & 20 & $4.10 \%$ \\
\hline Barometric Pressure $(\mathrm{mm} \mathrm{Hg})$ & & $\mathrm{n} / \mathrm{a}$ & 760.6 & 759.7 & & & & & & & & \\
\hline Temperature $\left({ }^{\circ} \mathrm{C}\right)$ & & 16.9 & 16.82 & 16.87 & & & & & & & & \\
\hline$\%$ Saturation & 16.00 & $7.12 \%$ & $14.90 \%$ & $14.90 \%$ & 50 & 120 & 130 & 1005 & 250 & $1.09 \mathrm{mg} / \mathrm{L}$ & 11 & $230^{\circ}$ \\
\hline Dissolved Oxygen (mg/L) & 10.00 & 0.69 & 1.44 & 1.45 & Jo & 120 & 100 & 1005 & 2.0070 & $\mathrm{BP}=760)$ & 11 & 2.0070 \\
\hline Barometric Pressure $(\mathrm{mm} \mathrm{Hg})$ & & $\mathrm{n} / \mathrm{a}$ & 760.5 & 759.6 & & & & & & & & \\
\hline Temperature $\left({ }^{\circ} \mathrm{C}\right)$ & & 16.86 & 16.78 & 16.83 & & & & & & & & \\
\hline \% Saturation & $16 \cdot 20$ & $1.31 \%$ & $8.20 \%$ & $8.30 \%$ & 20 & 120 & 40 & 1010 & $0.78 \%$ & $\begin{array}{l}0.36 \mathrm{mg} / \mathrm{L} \\
(\mathrm{T}=16.8\end{array}$ & 4 & $0.84 \%$ \\
\hline Dissolved Oxygen $(\mathrm{mg} / \mathrm{L})$ & 10.20 & 0.13 & 0.79 & 0.81 & 20 & & & & & $\mathrm{BP}=760)$ & & \\
\hline Barometric Pressure $(\mathrm{mm} \mathrm{Hg})$ & & $\mathrm{n} / \mathrm{a}$ & 760.3 & 759.5 & & & & & & & & \\
\hline Temperature $\left({ }^{\circ} \mathrm{C}\right)$ & & 16.75 & 16.67 & 16.72 & & & & & & & & \\
\hline \% Saturation & $16 \cdot 40$ & $0.10 \%$ & $5.90 \%$ & $6.20 \%$ & 10 & 50 & 20 & 1230 & 0320 & $0.15 \mathrm{mg} / \mathrm{L}$ & 2 & 年 \\
\hline Dissolved Oxygen (mg/L) & 10.40 & 0.01 & 0.57 & 0.61 & 10 & 50 & 20 & 1230 & $0.35 \%$ & $\mathrm{BP}=760)$ & 2 & $0.42 \%$ \\
\hline Barometric Pressure $(\mathrm{mm} \mathrm{Hg})$ & & $\mathrm{n} / \mathrm{a}$ & 760.5 & 759.6 & & & & & & & & \\
\hline Temperature $\left({ }^{\circ} \mathrm{C}\right)$ & & 17.67 & 17.59 & 17.64 & & & & & & & & \\
\hline \% Saturation & $17 \cdot 20$ & $97.31 \%$ & $97.60 \%$ & $96.10 \%$ & 65 & 10 & 180 & 0 & $5050^{\circ}$ & $9.33 \mathrm{mg} / \mathrm{L}$ & 07 & $20270 \%$ \\
\hline Dissolved Oxygen (mg/L) & 11.20 & 9.25 & 9.32 & 9.17 & (1) & 10 & 100 & 0 & 20.0070 & $\mathrm{BP}=760)$ & 年 & 20.2170 \\
\hline Barometric Pressure $(\mathrm{mm} \mathrm{Hg})$ & & $\mathrm{n} / \mathrm{a}$ & 760.5 & 759.6 & & & & & & & & \\
\hline
\end{tabular}


Table 4. Results Second Set Laboratory Testing

\begin{tabular}{|c|c|c|c|c|c|c|c|c|c|}
\hline & Time & $\begin{array}{l}\text { Aanderaa } \\
\text { ("Nemo") }\end{array}$ & $\begin{array}{c}\text { YSI } 600 \\
\text { XLM Sonde }\end{array}$ & $\begin{array}{l}\text { Rotameter } \\
\text { Air Setting }\end{array}$ & $\begin{array}{l}\text { Rotameter } \\
\text { N2 Setting }\end{array}$ & $\begin{array}{c}\text { Air Flow } \\
\text { Rate }^{2} \\
(\mathrm{~mL} / \mathrm{min})\end{array}$ & $\begin{array}{c}\text { N2 Flow } \\
\text { Rate }^{2} \\
(\mathrm{~mL} / \mathrm{min})\end{array}$ & $\begin{array}{c}\text { Calculated Inlet } \\
\text { Air O2\% by } \\
\text { volume (based } \\
\text { on flow rates) }\end{array}$ & $\begin{array}{c}\text { Calculated } \\
\text { O2 } \\
\text { Solubility } \\
\text { (Colt, 1984) }\end{array}$ \\
\hline Temperature $\left({ }^{\circ} \mathrm{C}\right)$ & \multirow{4}{*}{$14: 50$} & 17.94 & 17.86 & \multirow{4}{*}{\multicolumn{6}{|c|}{$\begin{array}{l}\text { in air-saturated solution (using aquarium pump) after initial calibration; } \\
\text { calculated } \mathrm{DO}=9.38\left(20.9 \% \mathrm{O}_{2} \text { in air, } \mathrm{T}=17.9, \mathrm{BP}=752.5\right)\end{array}$}} \\
\hline \% Saturation & & $98.80 \%$ & $98.90 \%$ & & & & & & \\
\hline Dissolved Oxygen (mg/L) & & 9.35 & 9.39 & & & & & & \\
\hline Barometric Pressure $(\mathrm{mm} \mathrm{Hg})$ & & $\mathrm{n} / \mathrm{a}$ & 752.4 & & & & & & \\
\hline Temperature $\left({ }^{\circ} \mathrm{C}\right)$ & \multirow{4}{*}{$15: 05$} & 18.00 & 17.92 & \multirow{4}{*}{65} & \multirow{4}{*}{0} & \multirow{4}{*}{190} & \multirow{4}{*}{0} & \multirow{4}{*}{$20.00 \%$} & \multirow{4}{*}{$\begin{array}{l}8.96 \mathrm{mg} / \mathrm{L} \\
(\mathrm{T}=18 ; \\
\mathrm{BP}=752.5)\end{array}$} \\
\hline \% Saturation & & $96 \%$ & $95 \%$ & & & & & & \\
\hline Dissolved Oxygen (mg/L) & & 9.08 & 9.03 & & & & & & \\
\hline Barometric Pressure $(\mathrm{mm} \mathrm{Hg})$ & & $\mathrm{n} / \mathrm{a}$ & 752.5 & & & & & & \\
\hline Temperature $\left({ }^{\circ} \mathbf{C}\right)$ & \multirow{4}{*}{$15: 25$} & 18.06 & 17.98 & \multirow{4}{*}{65} & \multirow{4}{*}{0} & \multirow{4}{*}{190} & \multirow{4}{*}{0} & \multirow{4}{*}{$20.00 \%$} & \multirow{4}{*}{$\begin{array}{l}8.96 \mathrm{mg} / \mathrm{L} \\
(\mathrm{T}=18 ; \\
\mathrm{BP}=752.5)\end{array}$} \\
\hline \% Saturation & & $94.30 \%$ & $93 \%$ & & & & & & \\
\hline Dissolved Oxygen (mg/L) & & 8.90 & 8.83 & & & & & & \\
\hline Barometric Pressure (mm Hg) & & $\mathrm{n} / \mathrm{a}$ & 752.5 & & & & & & \\
\hline Temperature $\left({ }^{\circ} \mathrm{C}\right)$ & \multirow{4}{*}{$16: 00$} & 18.03 & 17.95 & \multirow{4}{*}{65} & \multirow{4}{*}{10} & \multirow{4}{*}{190} & \multirow{4}{*}{250} & \multirow{4}{*}{$8.64 \%$} & \multirow{4}{*}{$\begin{array}{c}3.88 \mathrm{mg} / \mathrm{L} \\
(\mathrm{T}=18 ; \\
\mathrm{BP}=752.5)\end{array}$} \\
\hline \% Saturation & & $42.10 \%$ & $44.00 \%$ & & & & & & \\
\hline Dissolved Oxygen (mg/L) & & 3.97 & 4.21 & & & & & & \\
\hline Barometric Pressure $(\mathrm{mm} \mathrm{Hg})$ & & $\mathrm{n} / \mathrm{a}$ & 752.3 & & & & & & \\
\hline Temperature $\left({ }^{\circ} \mathrm{C}\right)$ & \multirow{4}{*}{$17: 00$} & 18.02 & 17.94 & \multirow{4}{*}{20} & \multirow{4}{*}{120} & \multirow{4}{*}{40} & \multirow{4}{*}{1020} & & \\
\hline \% Saturation & & $4.22 \%$ & $5.60 \%$ & & & & & $075 \%$ & $0.34 \mathrm{mg} / \mathrm{L}$ \\
\hline Dissolved Oxygen (mg/L) & & 0.4 & 0.53 & & & & & $0.15 \%$ & $\begin{array}{c}(1=18 \\
\mathrm{BP}=7526)\end{array}$ \\
\hline Barometric Pressure $(\mathrm{mm} \mathrm{Hg})$ & & $\mathrm{n} / \mathrm{a}$ & 752.6 & & & & & & \\
\hline Temperature $\left({ }^{\circ} \mathrm{C}\right)$ & & 18.12 & 18.01 & & & & & & \\
\hline \% Saturation & $17 \cdot 10$ & $-0.33 \%$ & $0.30 \%$ & & & 1. & & & \\
\hline Dissolved Oxygen (mg/L) & $1 /: 10$ & -0.03 & 0.03 & & & placed in so & num suinte & solution & \\
\hline Barometric Pressure $(\mathrm{mm} \mathrm{Hg})$ & & $\mathrm{n} / \mathrm{a}$ & 752.5 & & & & & & \\
\hline Temperature $\left({ }^{\circ} \mathrm{C}\right)$ & & 17.96 & 17.89 & & & & & & \\
\hline \% Saturation & $17 \cdot 35$ & $98.97 \%$ & $99.40 \%$ & in air-satur & rated solutio & $\mathrm{n}$ (using aqu & arium pump & ); calculated DO = & $=9.38(20.9 \%$ \\
\hline Dissolved Oxygen (mg/L) & $1 / .35$ & 9.36 & 9.43 & & & $\mathrm{O}_{2}$ in air, & $=17.9, \mathrm{BP}=7$ & $752.5)$ & \\
\hline Barometric Pressure $(\mathrm{mm} \mathrm{Hg})$ & & $\mathrm{n} / \mathrm{a}$ & 752.5 & & & & & & \\
\hline $\begin{array}{l}{ }^{1} \mathrm{~T}=\text { temperature }\left({ }^{\circ} \mathrm{C}\right) ; \mathrm{BP}=\mathrm{ba} \\
\text { instruments }\end{array}$ & ric & sure $(\mathrm{mmH}$ & $\mathrm{Ig}$ ); values us & sed are base & d on reading & s from the & lermometer, & Druck DPI and D & \\
\hline${ }^{2}$ Flow rates based on digital flo & eter: & esults fron & bubble fil & alibration & test & & & & \\
\hline Assuming inlet flow contain & 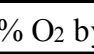 & 1) & & & & & & & \\
\hline
\end{tabular}


Table 5. Well Information for CRP42B at CBRP

\begin{tabular}{|c|c|}
\hline Year Installed & 2000 \\
\hline Casing Type & PVC \\
\hline Well Depth (TOC) ${ }^{1}$ & $12.33^{\prime}$ \\
\hline Casing Height & $4.7^{\prime}$ \\
\hline Well Diameter & $2 "$ \\
\hline Screen Length & $3^{\prime}$ \\
\hline Sump & 4" \\
\hline Range Water Depth (TOC) ${ }^{2}$ & $5.8^{\prime}-7^{\prime}$ \\
\hline Range Measured D.O. ${ }^{3}$ & $1.3-4 \mathrm{mg} / \mathrm{L}$ \\
\hline \multicolumn{2}{|l|}{${ }^{1}$ TOC=Top of Casing } \\
\hline \multicolumn{2}{|c|}{${ }^{2}$ range includes 2002-2005 measurements } \\
\hline \multicolumn{2}{|c|}{${ }^{3}$ range includes 2002-2005 measurements for CRP42B } \\
\hline
\end{tabular}

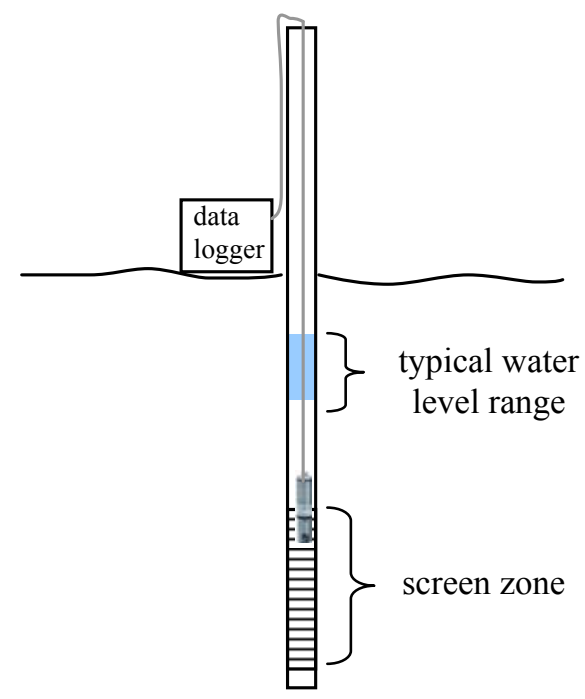

Table 6. Summary D.O., Temperature, Battery Power at CBRP

\begin{tabular}{|c|c|c|c|c|c|c|c|}
\hline Month & Avg DO & Min DO & Max DO & Avg Temp & Min Temp & Max Temp & Avg Battery \\
\hline Jan_2005 & 1.01 & 0.81 & 1.79 & 16.48 & 15.95 & 16.95 & 12.02 \\
\hline Feb_2005* & 0.94 & 0.00 & 2.90 & 16.06 & 12.18 & 18.41 & 12.18 \\
\hline May_2005 & 0.36 & 0.07 & 1.01 & 17.16 & 16.78 & 17.60 & 12.31 \\
\hline June_2005 & 0.04 & 0.00 & 0.23 & 18.19 & 17.43 & 18.58 & 12.00 \\
\hline July_2005 & 0.01 & 0.00 & 0.31 & 19.16 & 18.58 & 19.72 & 12.41 \\
\hline August_2005 & 0.00 & 0.00 & 0.07 & 20.12 & 19.72 & 20.55 & 12.56 \\
\hline September_2005 & 0.15 & 0.00 & 0.46 & 20.27 & 20.22 & 21.20 & 12.56 \\
\hline October_2005 & 0.25 & 0.00 & 1.79 & 20.19 & 20.05 & 20.39 & 12.04 \\
\hline November_2005 & 0.77 & 0.62 & 0.93 & 18.81 & 18.26 & 19.08 & 11.76 \\
\hline December_2005 & 0.75 & 0.54 & 0.93 & 17.65 & 16.78 & 18.41 & 11.78 \\
\hline January_2005 & 0.61 & 0.46 & 0.93 & 16.95 & 16.78 & 17.43 & 11.82 \\
\hline $\begin{array}{l}\text { *maximum DO reflects activities associated with the Push-Pull tests; data periods in which optode was taken out of CRP42B were } \\
\text { removed from the dataset }\end{array}$ \\
\hline \multicolumn{7}{|l|}{} \\
\hline
\end{tabular}


Table 7. Well Information for PGW24C at P Reactor Area

\begin{tabular}{|c|c|}
\hline Casing Type & PVC \\
\hline Approximate Well Depth (TOC) ${ }^{1}$ & $112^{\prime}$ \\
\hline Casing Height & $2.5^{\prime}$ \\
\hline Well Diameter & $2^{\prime \prime}$ \\
\hline Screen Length & $10^{\prime}$ \\
\hline Range Water Depth ${ }^{2}$ (TOC) & $47.0-52.2^{\prime}$ \\
\hline Range Measured D.O. ${ }^{2}$ & $1.80-3.57 \mathrm{mg} / \mathrm{L}$ \\
\hline \multicolumn{2}{|l|}{ TOC=Top of Casing; well depth assuming $2.5^{\prime}$ sump } \\
\hline
\end{tabular}

Table 8. Summary D.O. at PGW24C

\begin{tabular}{|c|c|c|c|c|}
\hline Month & Avg DO & Min DO & Max DO & \# Measurements \\
\hline May_2005* & 0.17 & 0.15 & 0.23 & 1478 \\
\hline June_2005 & 0.08 & 0.07 & 0.15 & 2806 \\
\hline July_2005 & 0.05 & 0.00 & 0.07 & 2969 \\
\hline August_2005 & 0.01 & 0.00 & 0.07 & 2972 \\
\hline September_2005 & 0.04 & 0.00 & 0.07 & 2877 \\
\hline October_2005 & 0.07 & 0.00 & 0.23 & 2979 \\
\hline November_2005 & 0.07 & 0.07 & 0.07 & 2877 \\
\hline December_2005 & 0.07 & 0.00 & 0.07 & 2976 \\
\hline January_2006 & 0.07 & 0.07 & 0.07 & 1690 \\
\hline
\end{tabular}

*values reflect readings of instrument as it was deployed spurious data points removed from dataset 
Figure 1. Schematic of Fluorescence Quenching

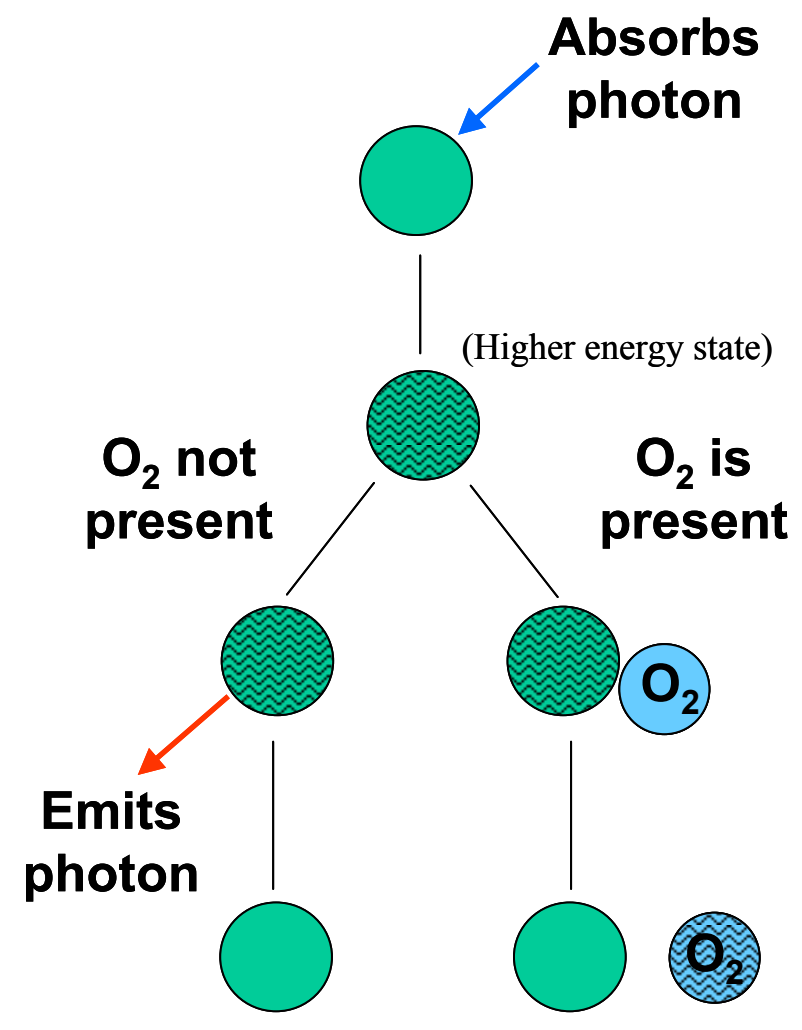

Figure 2. Oxygen Optode Sensing Foil

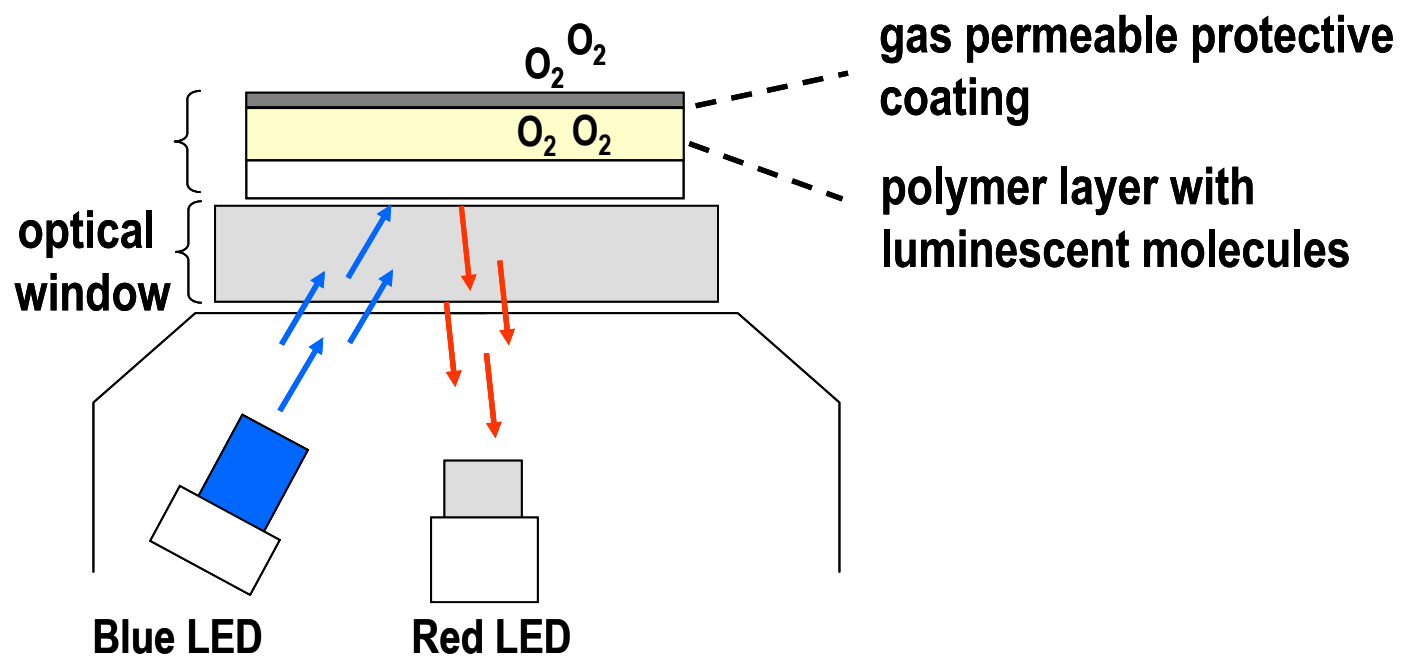


Figure 3. Aanderaa performance at Belleville Lake, MI, ACT Comparative Study

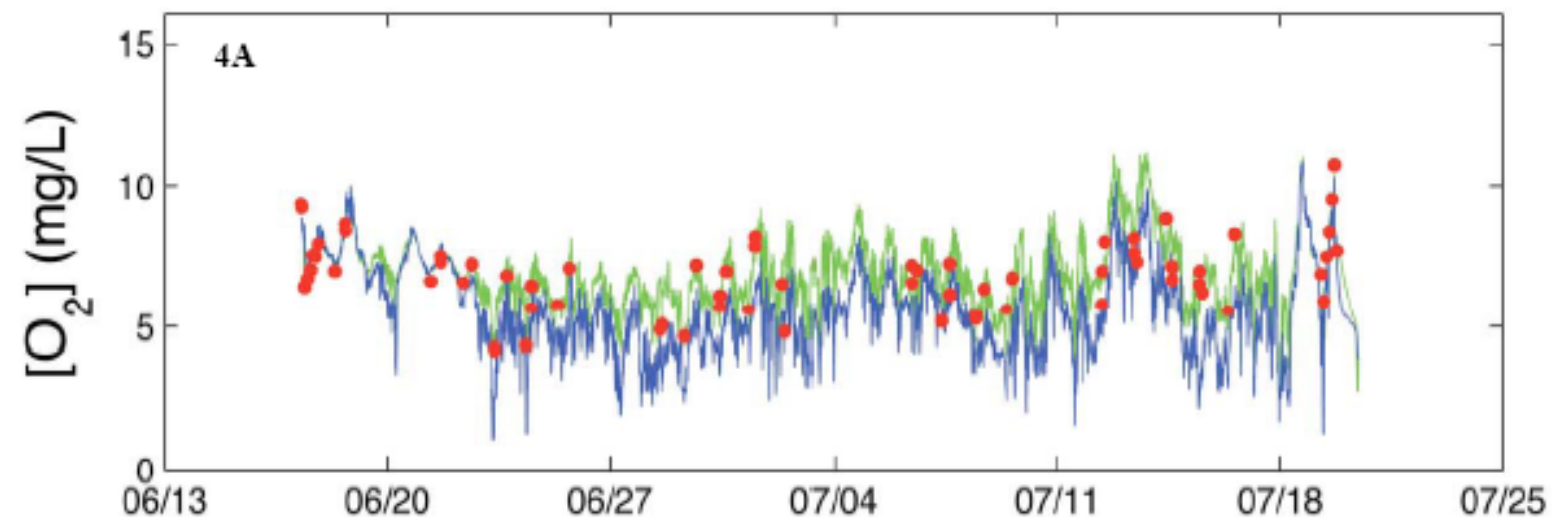

Aanderaa performance at Belleville Lake, MI, the only freshwater field location in this study. Salinity ranged from $0-0.1 \mathrm{ppt}$ and temperature varied from $22.5-27.1^{\circ} \mathrm{C}$. Green line $=$ sensor without biofouling shield; blue line $=$ sensor with biofouling shield; red dots $=$ Winkler titration DO mean $(n=3)$.

Figure 4. Initial Laboratory Setup
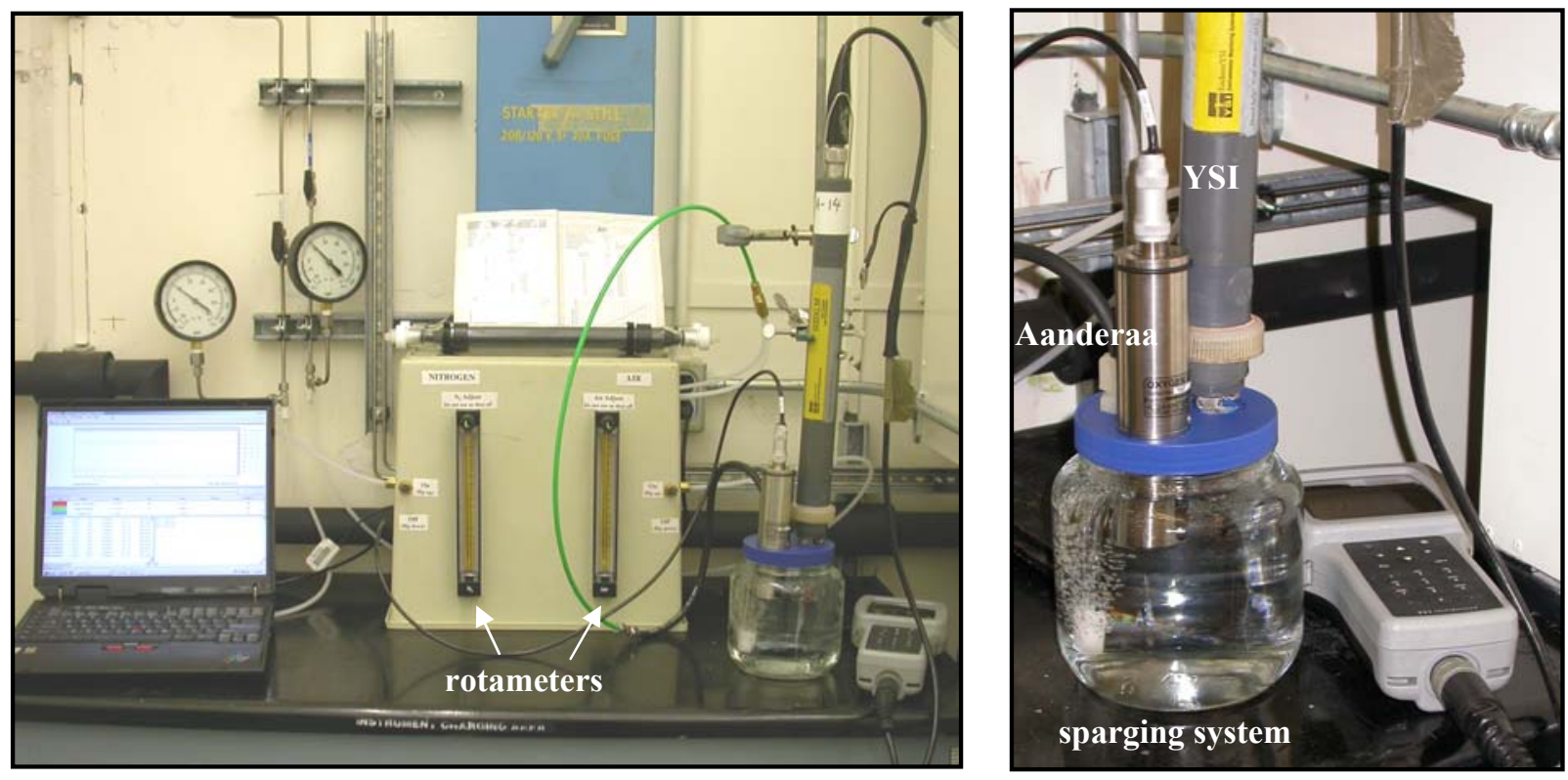
Figure 5. Comparing Calculations for Oxygen Solubility

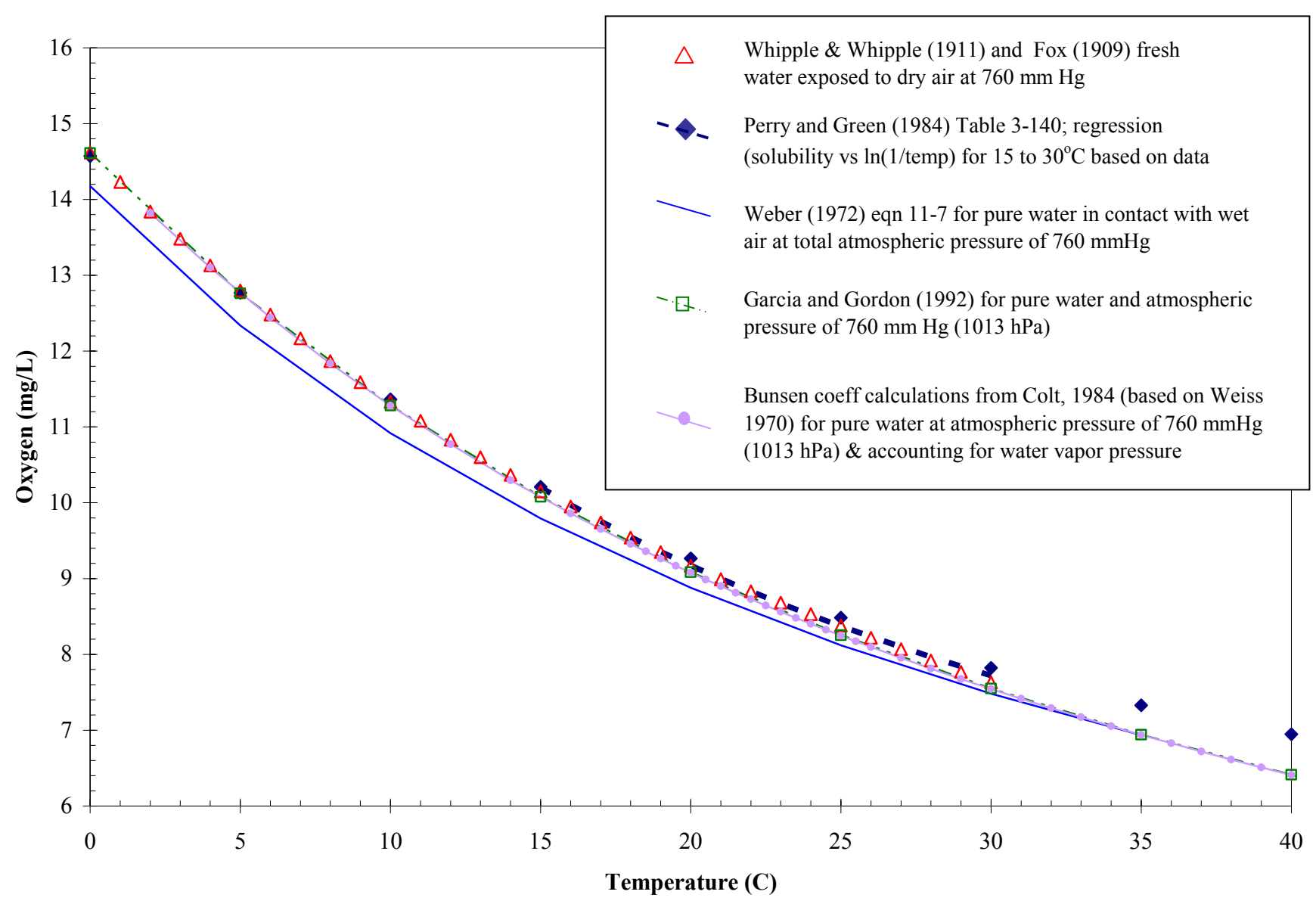


Figure 6. Setup of First Set of Laboratory Tests

Cole Parmer

Rotameters

$$
\begin{array}{|l|l|}
\otimes & \oplus \\
\hline- & - \\
\hline- & - \\
\hline- & \bar{\theta} \\
\hline \bar{\theta} & \underline{-} \\
\hline &
\end{array}
$$
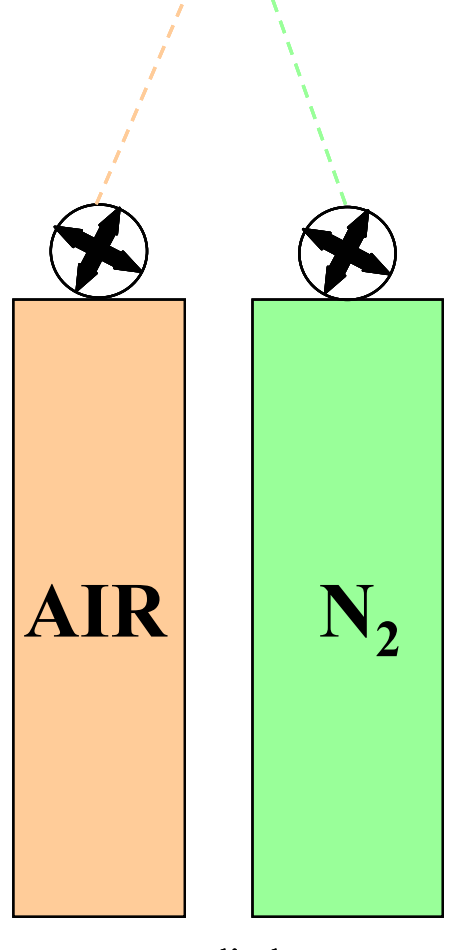

gas cylinders
Sierra Instrument Inc

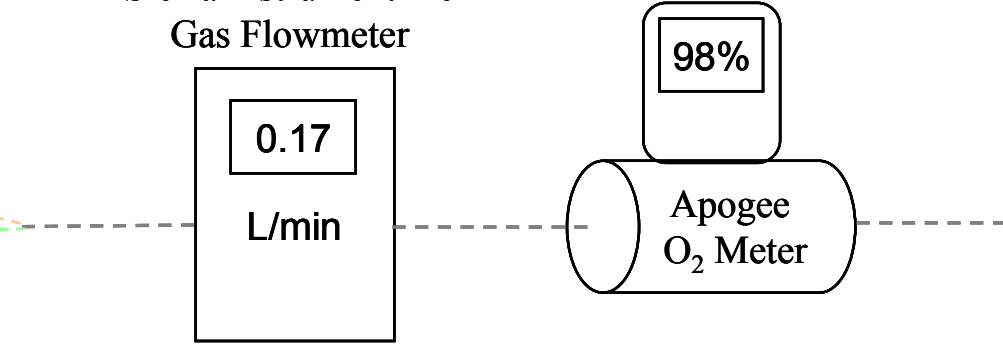

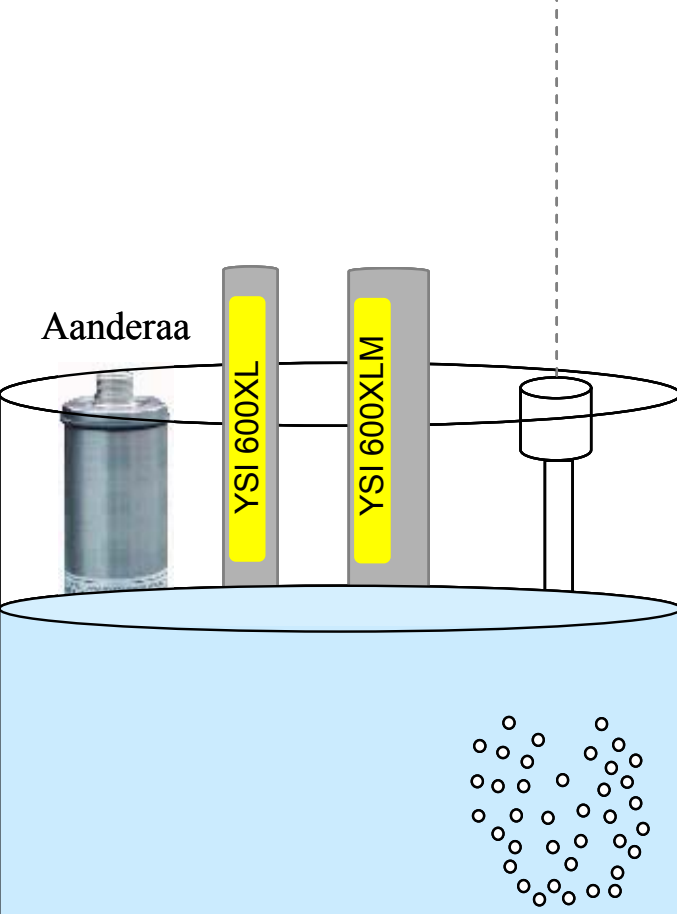

sparger 
Figure 7. D.O. Results from First Set of Laboratory Testing

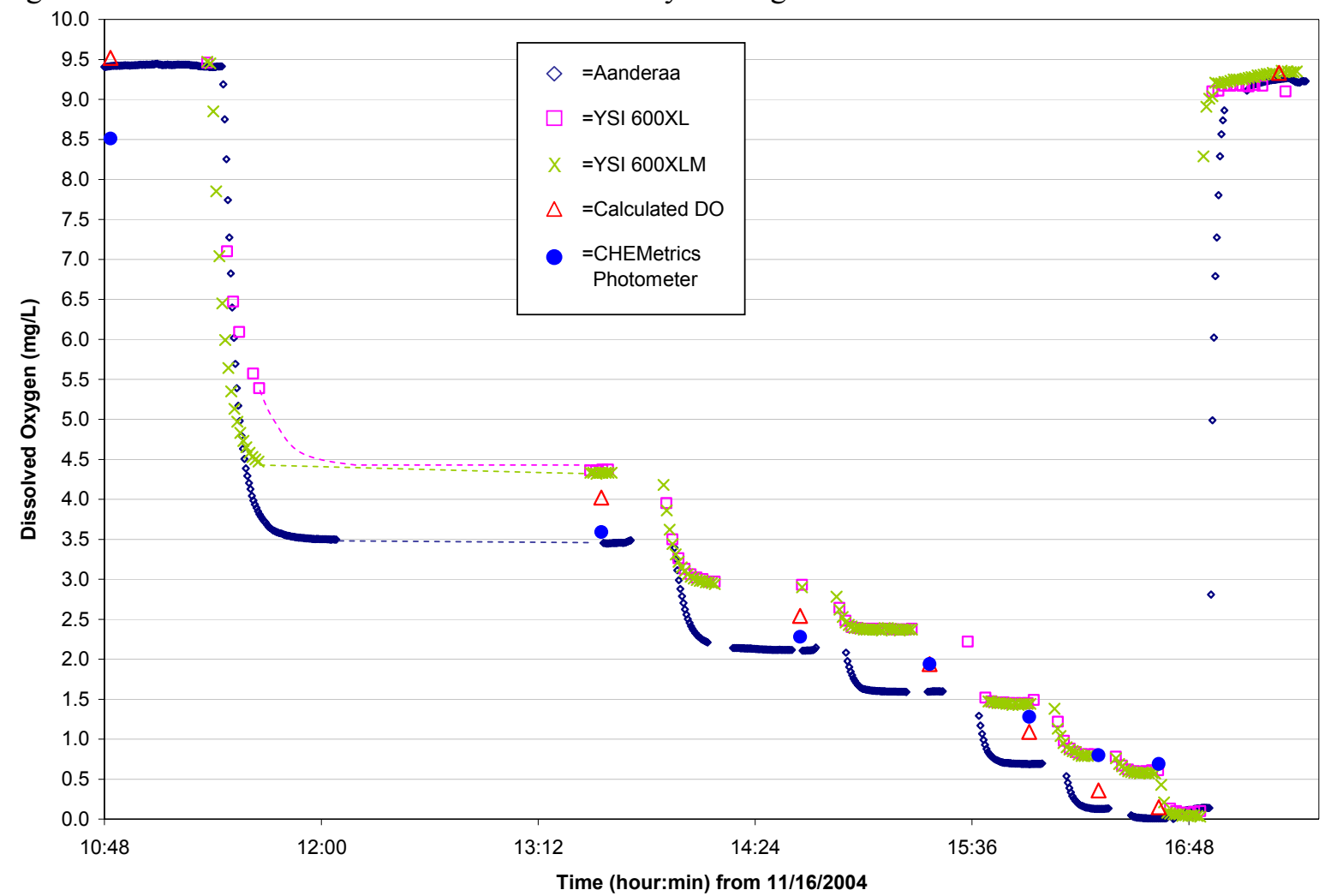

Figure 8. D.O. Results (0-3 mg/L) from First Set of Laboratory Testing

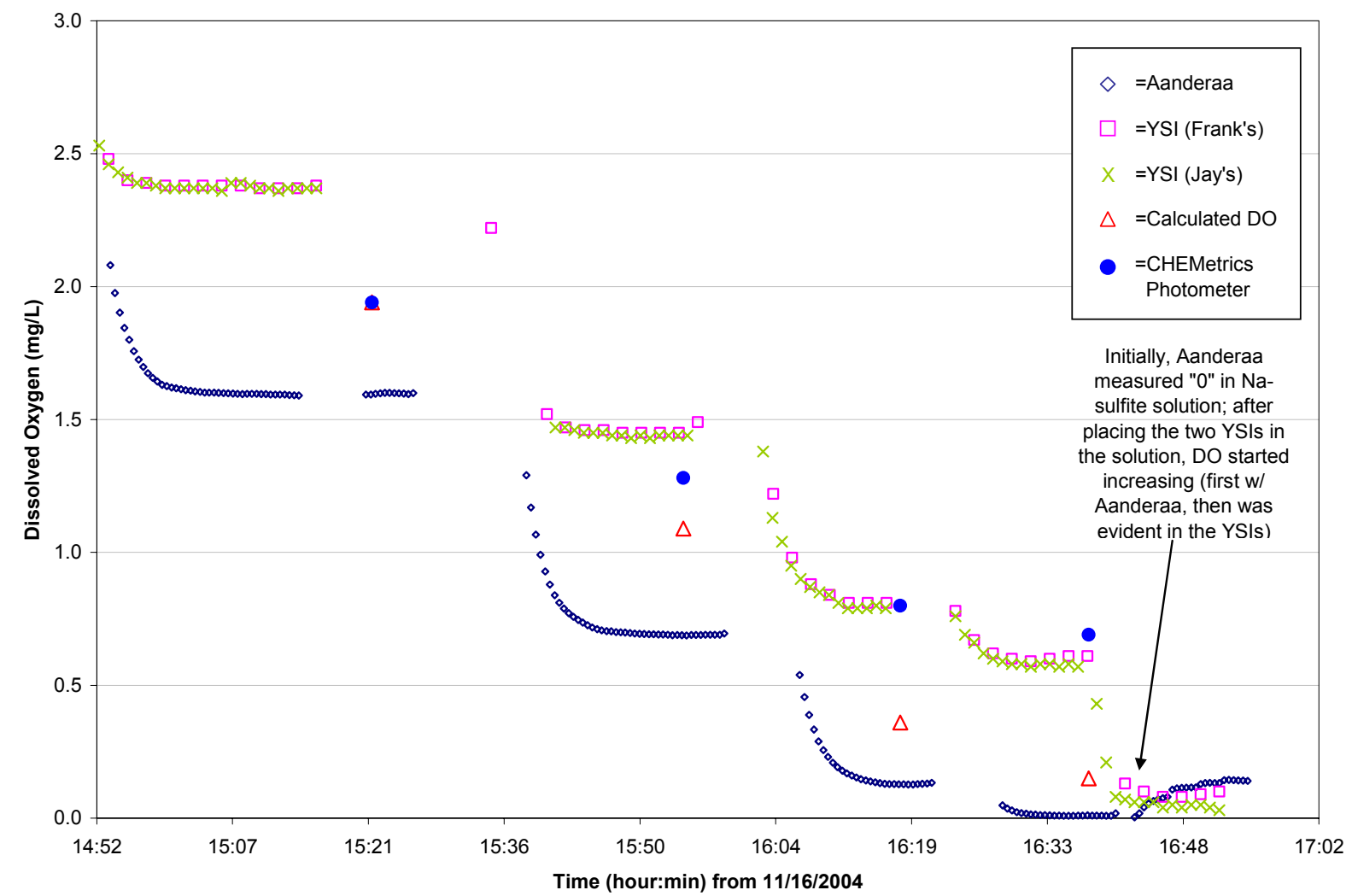


Figure 9. Setup of Second Set of Laboratory Tests

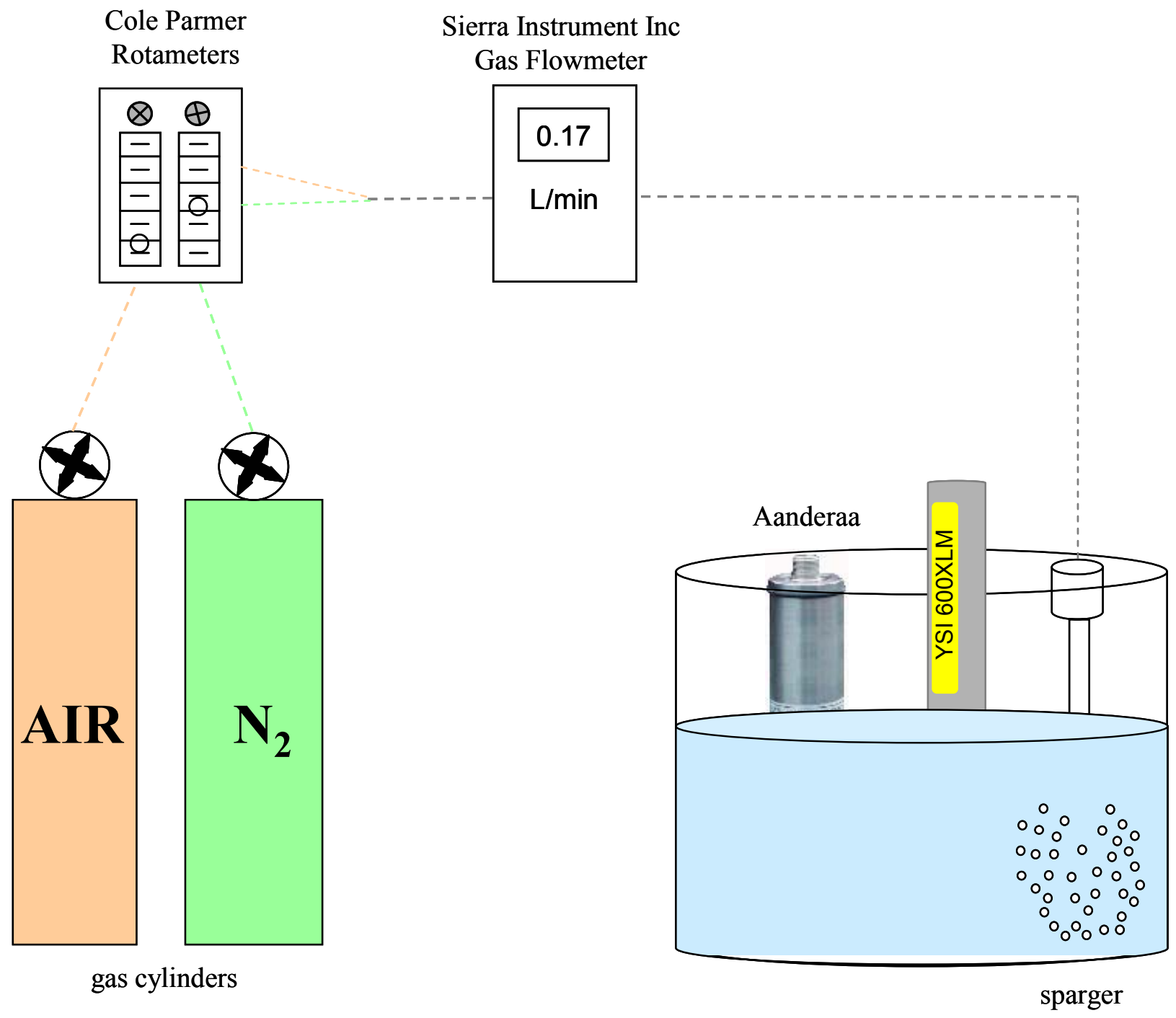


Figure 10. D.O. Results from Second Set of Laboratory Testing

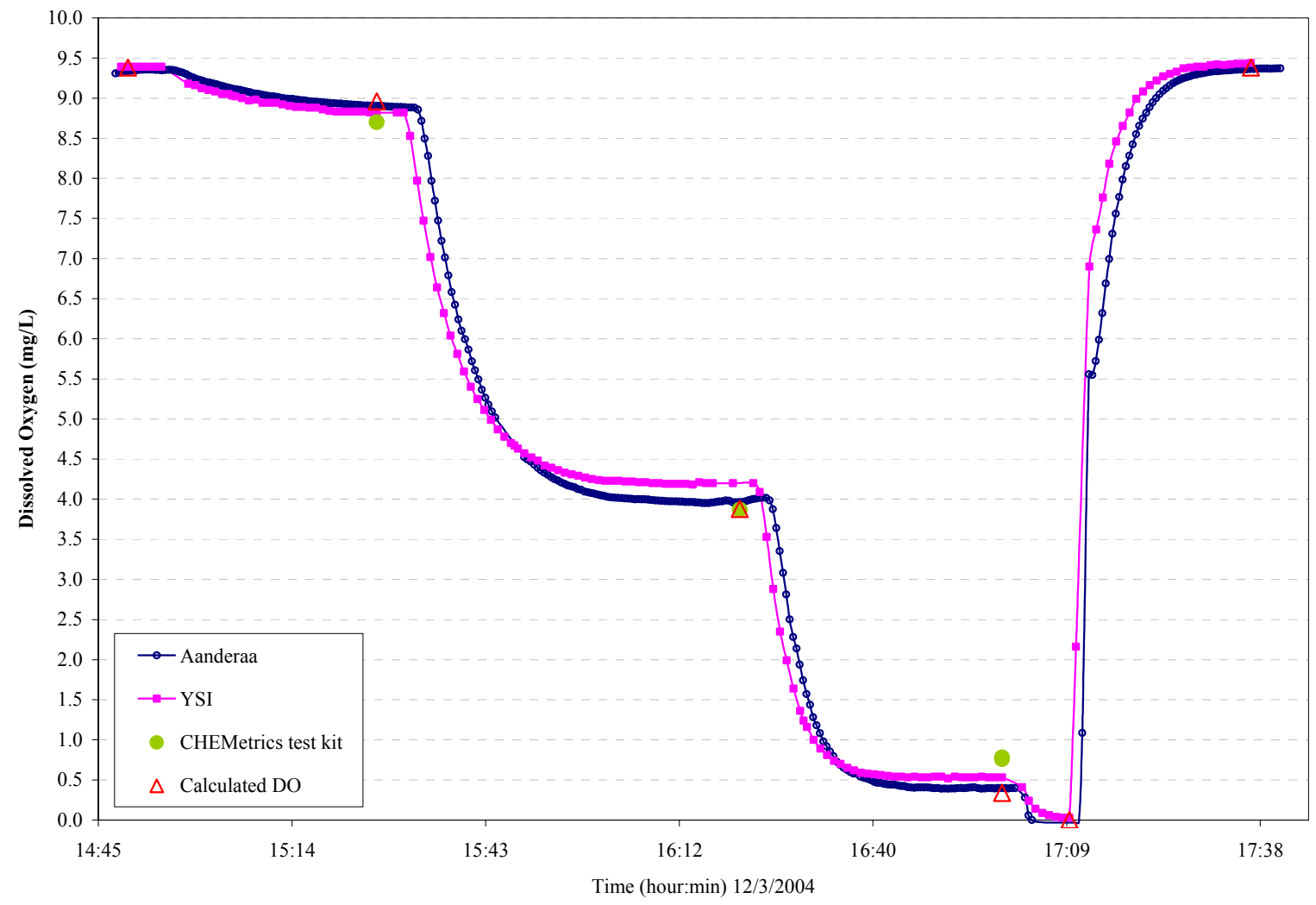


Figure 11. Calibration Data Logging System for CBRP

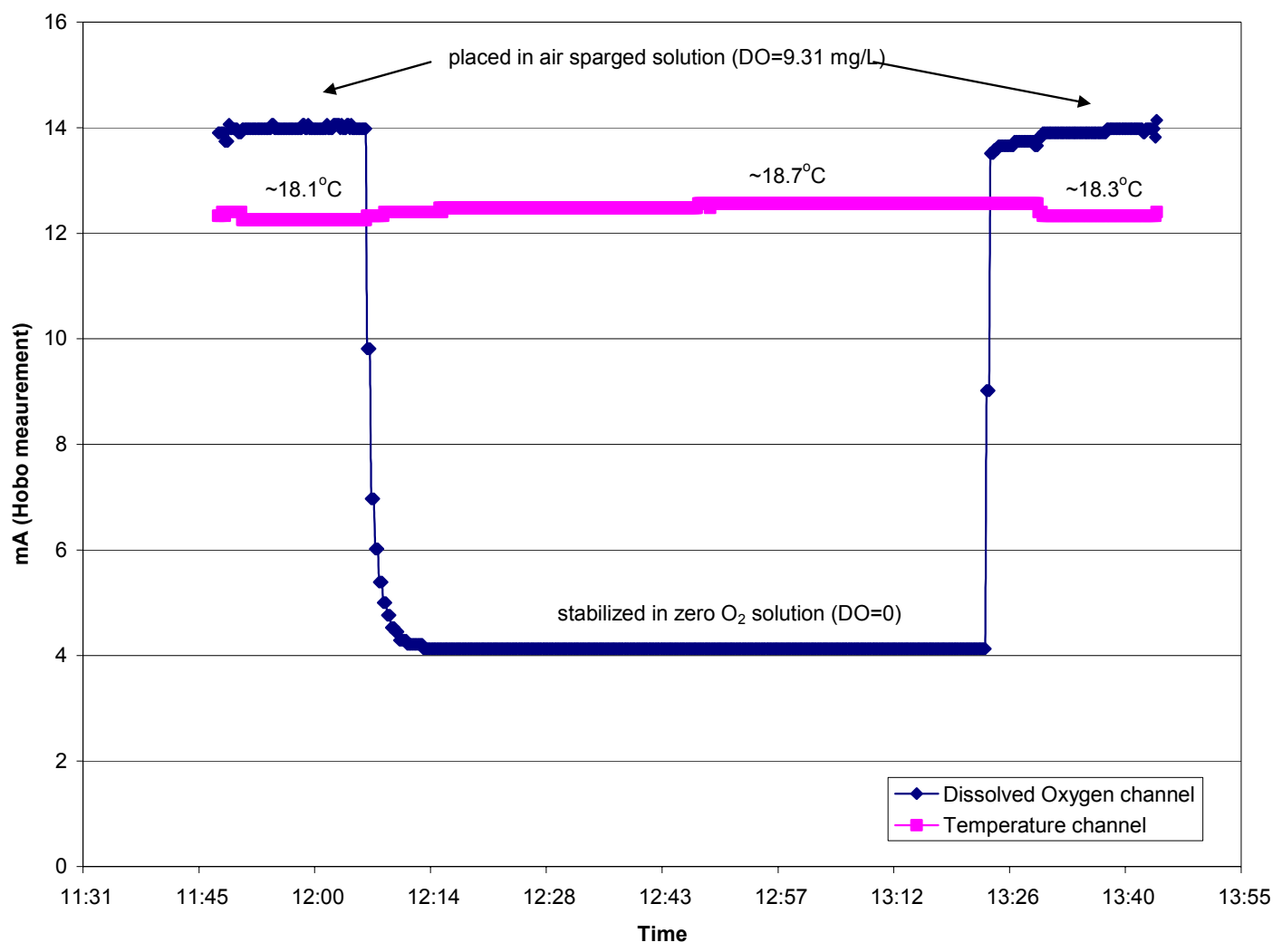


Figure 12. Location of CRP42B in relation to TCE Plume at CBRP

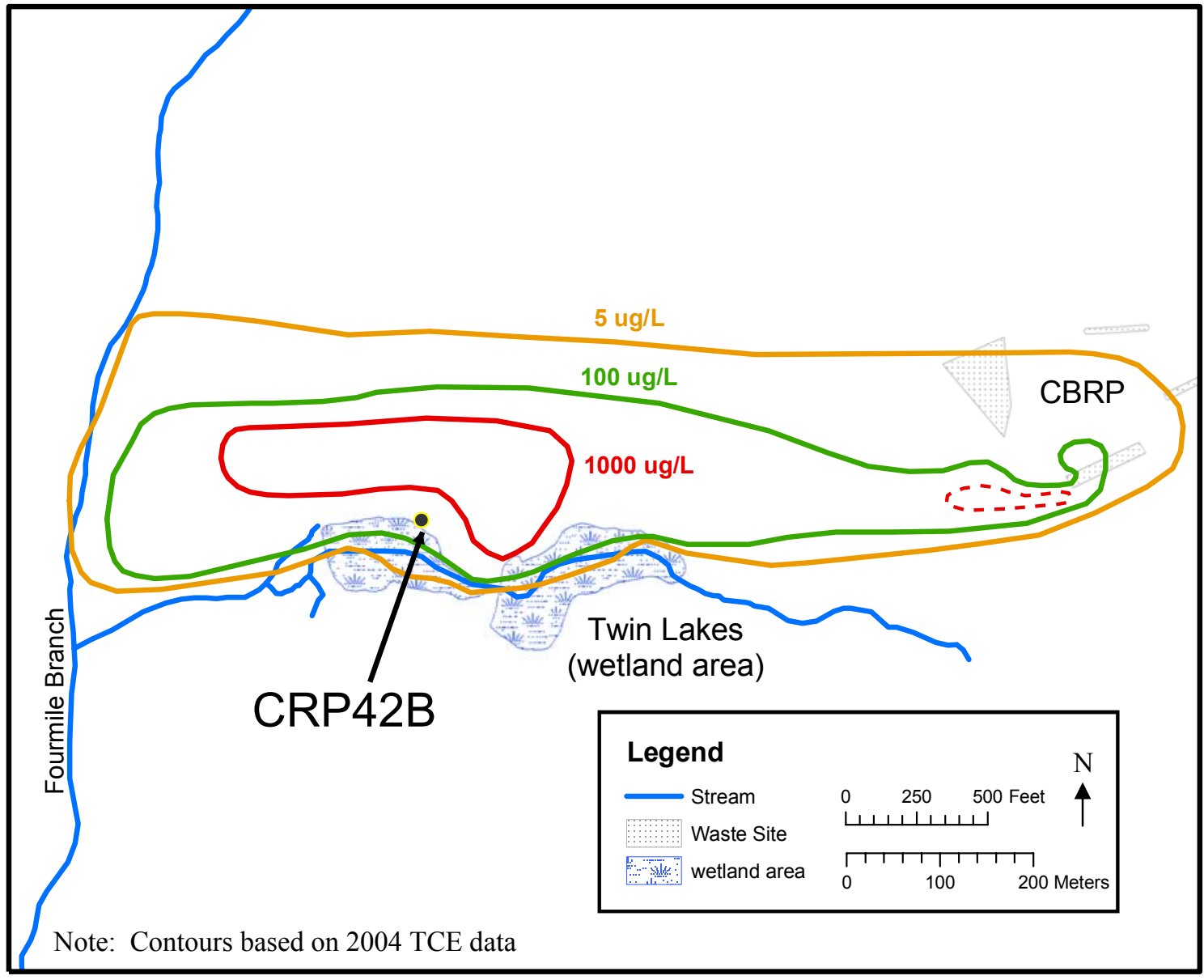


Figure 13. CRP42B DO Monitoring January 2005

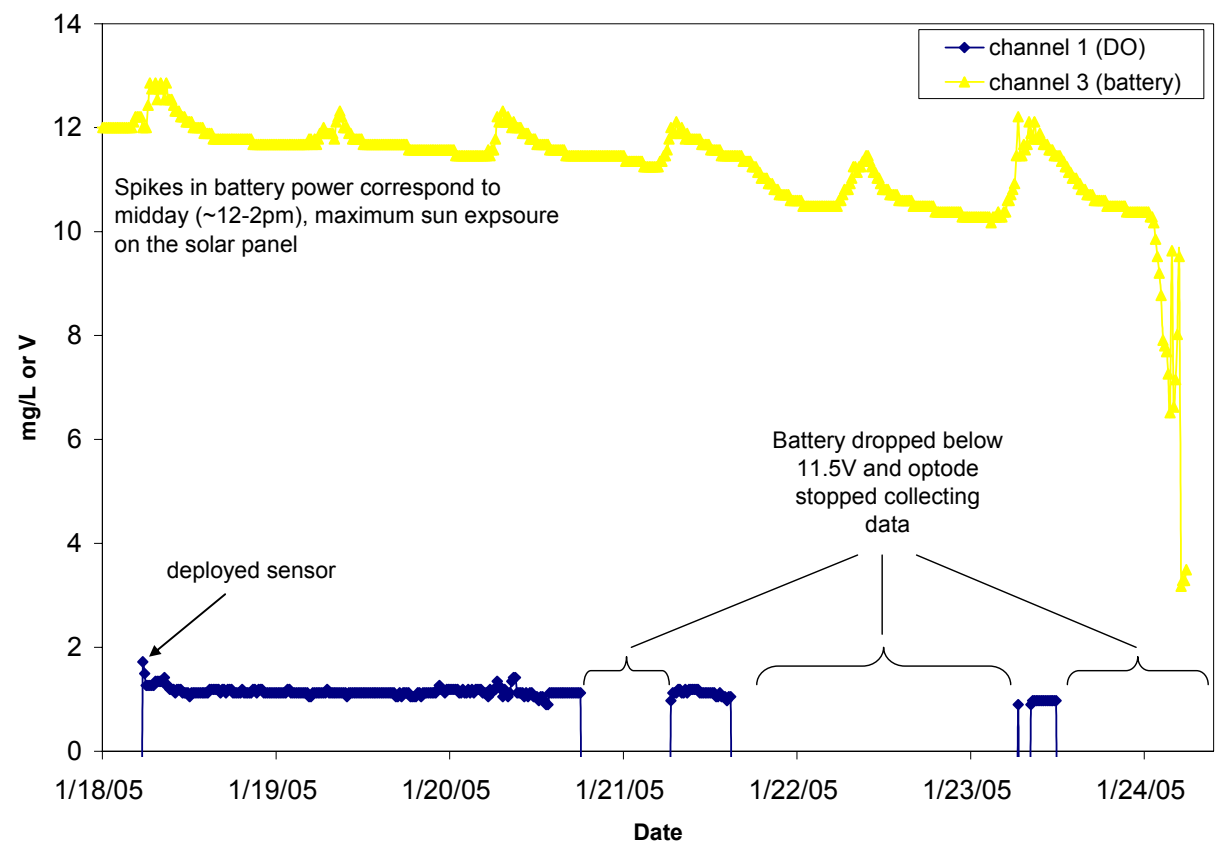

Figure 14. CRP42B DO Monitoring February 2005

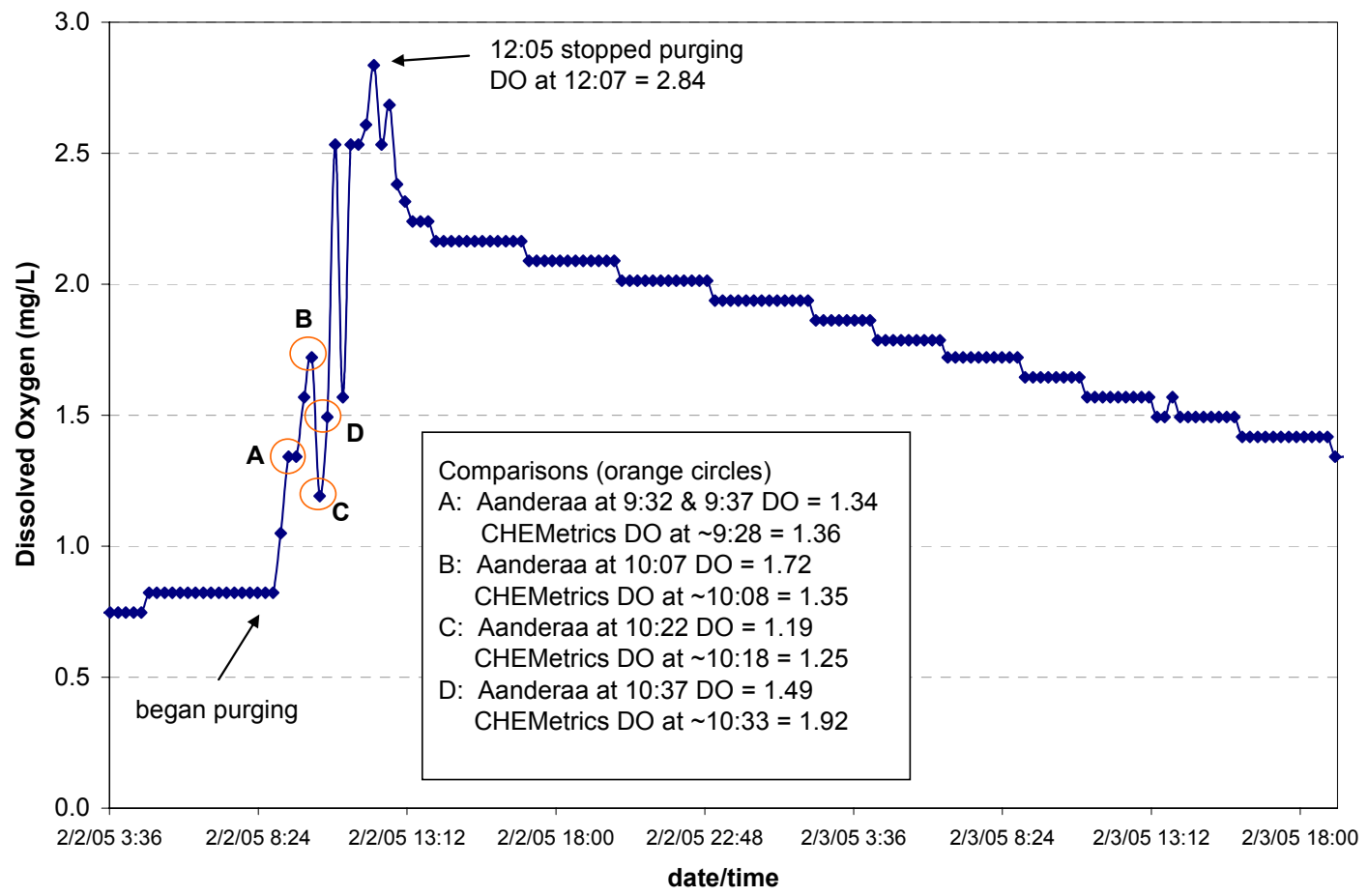

*Note: Aanderaa sample interval set for 15 minute intervals; therefore sample collection times for the Aanderaa and CHEMetrics are not the same. 
Figure 15. Dissolved Oxygen Concentrations in CRP42B after Redeployment of Optode

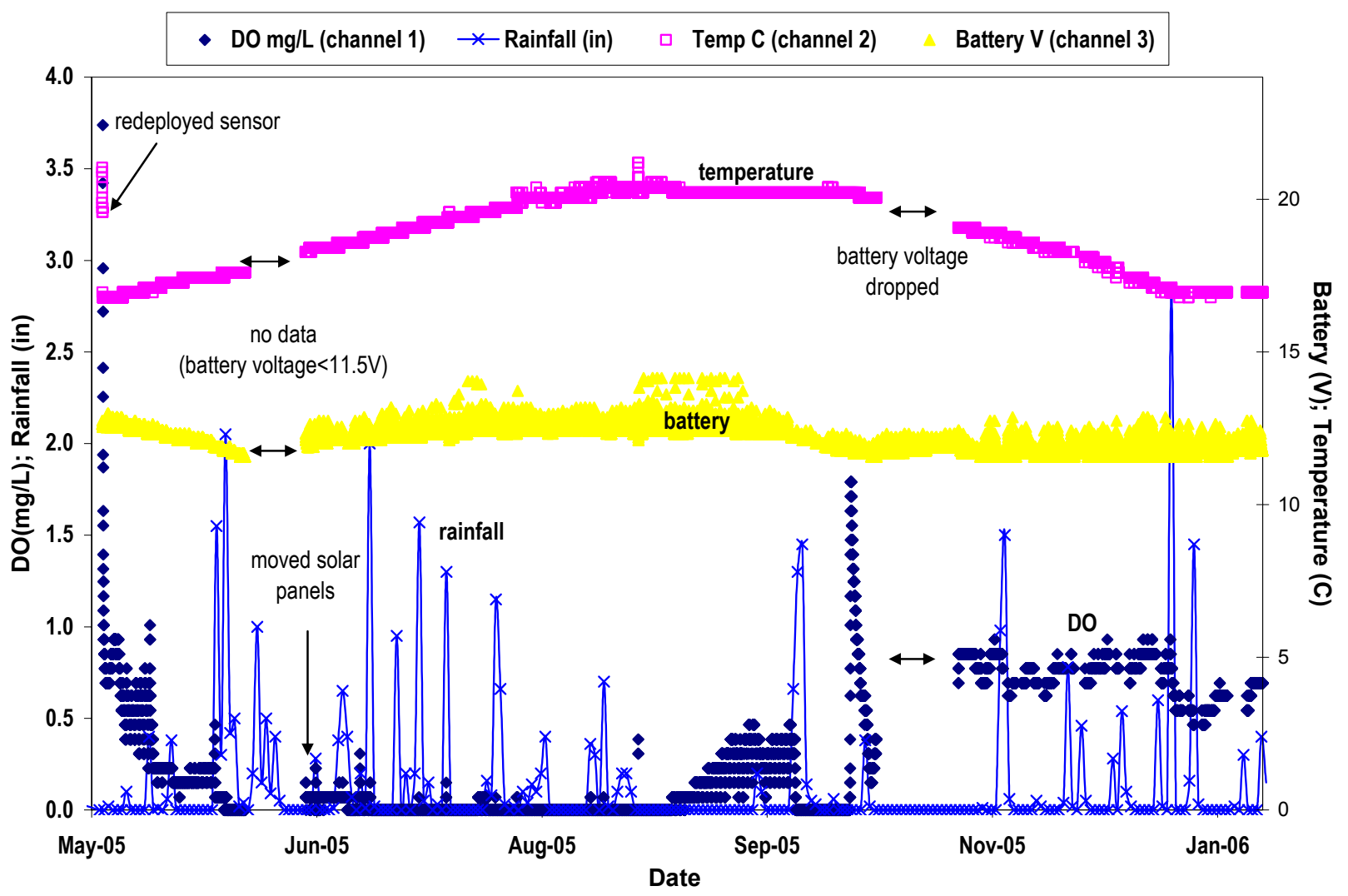


Figure 16. Location of PGW24C in P Reactor Area

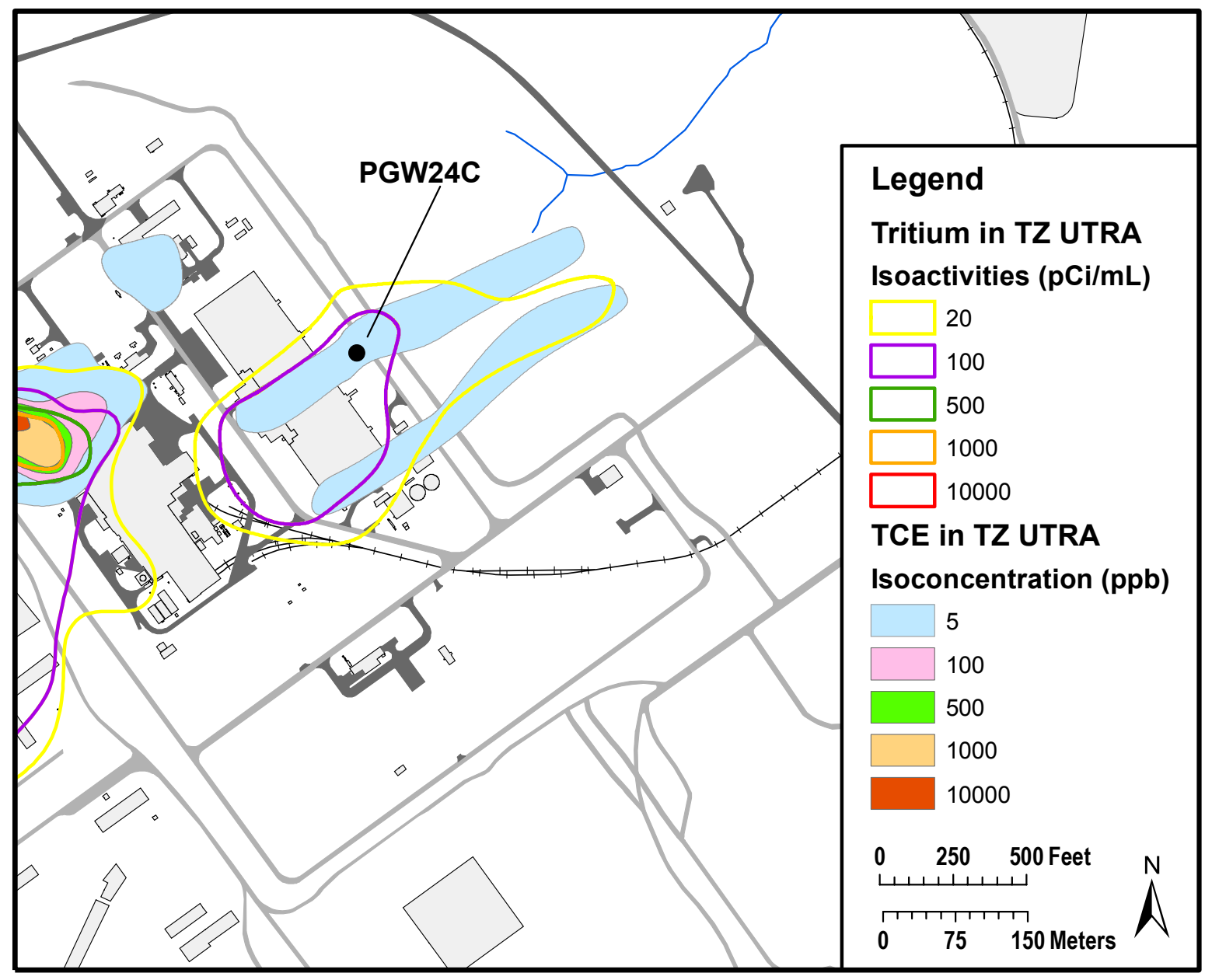


Figure 17. Results from Initial Testing at PGW24C

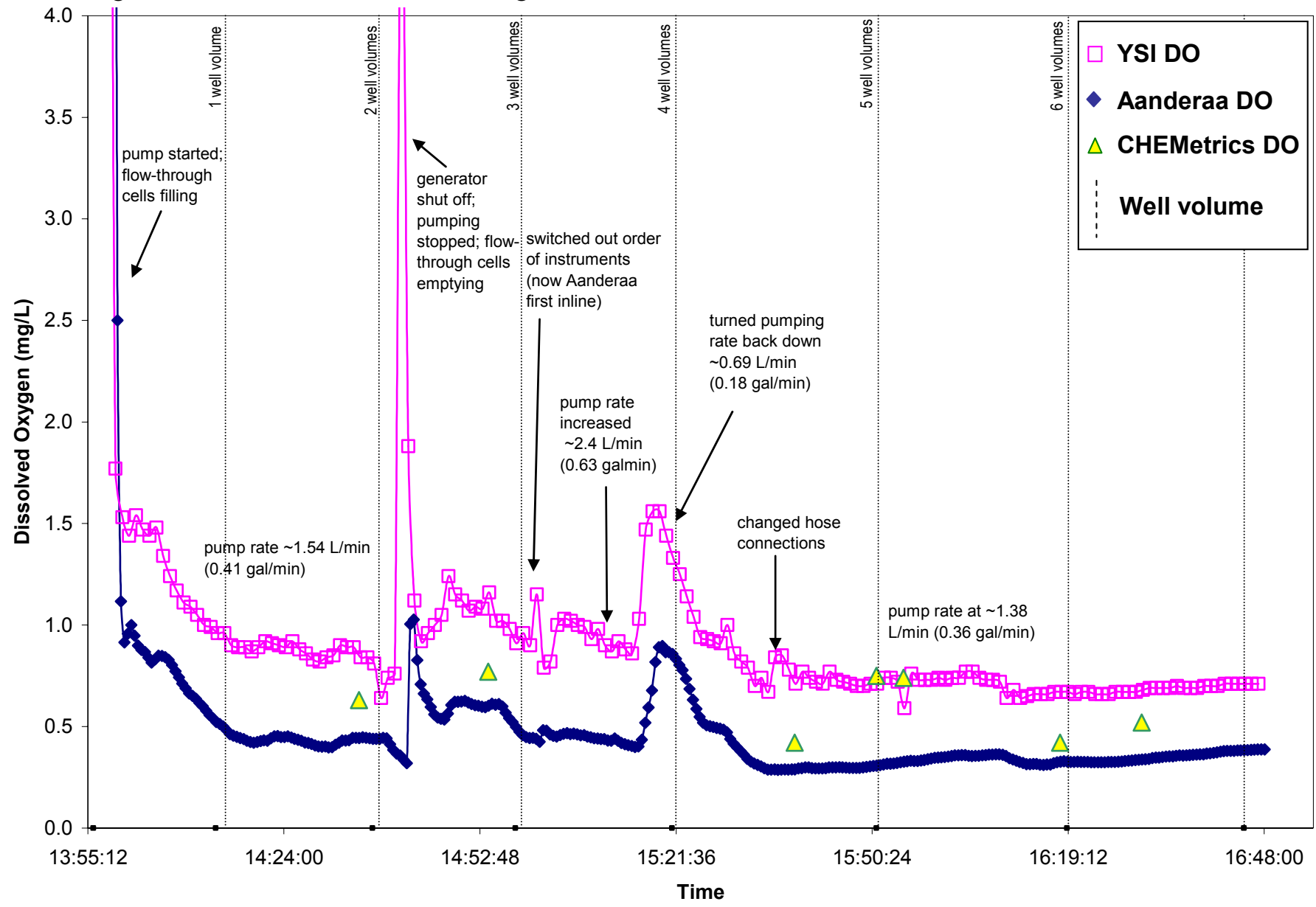


Figure 18. Results of Field Measurement Depth Profile Using YSI in PGW24C
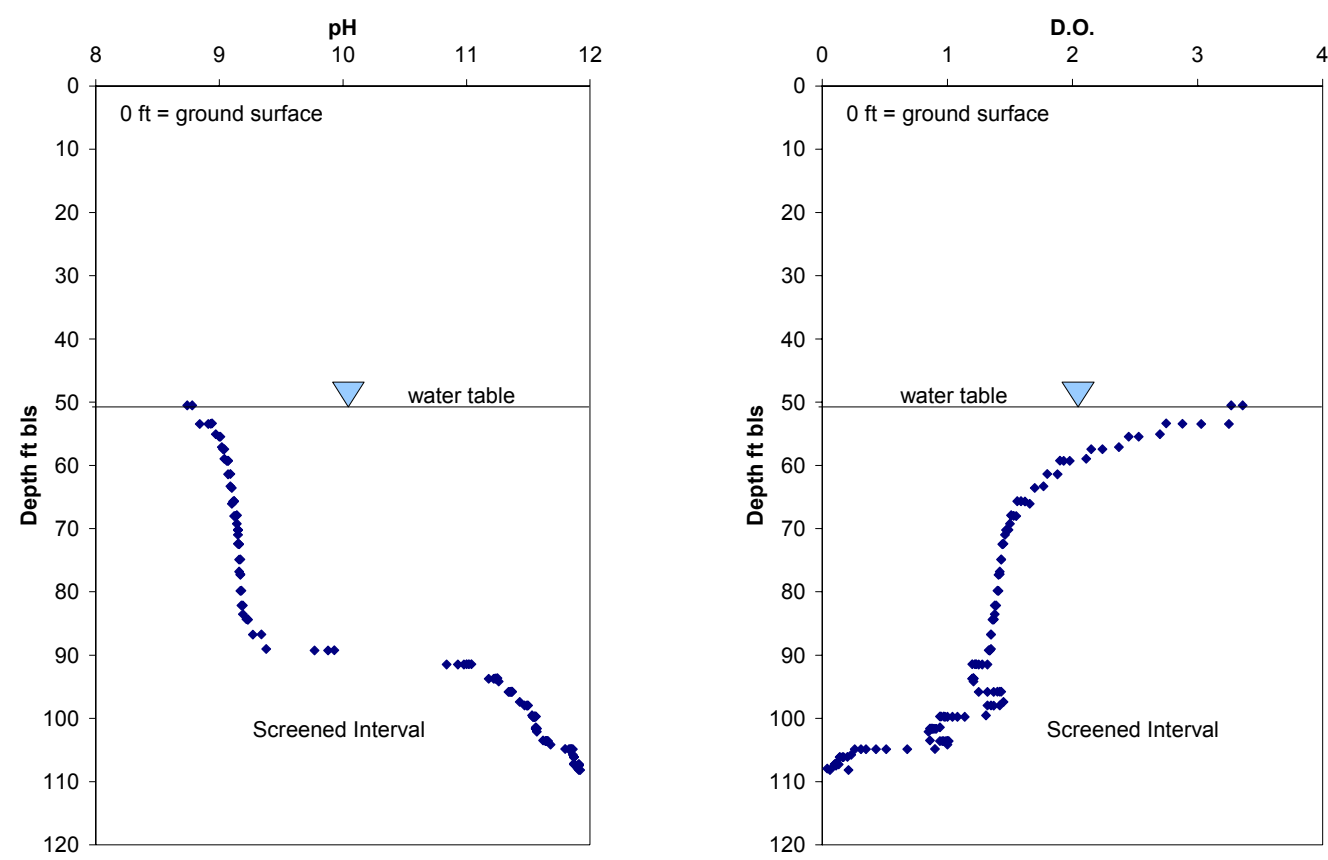
Figure 19. Installation of Bladder Pump, Aanderaa Optode, and data logging system at PGW24C
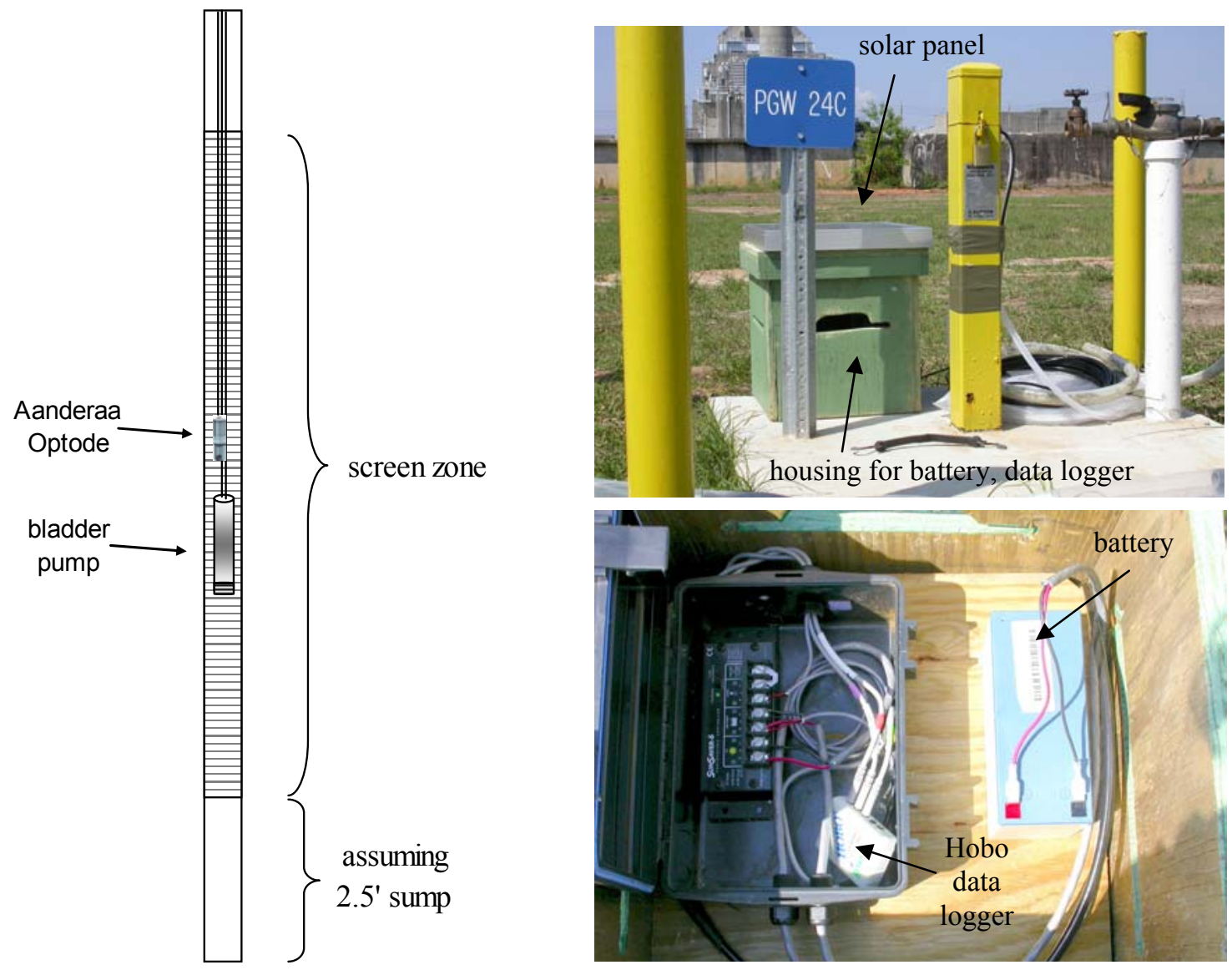
Figure 20. Results from Deployment of Optode in PGW24C

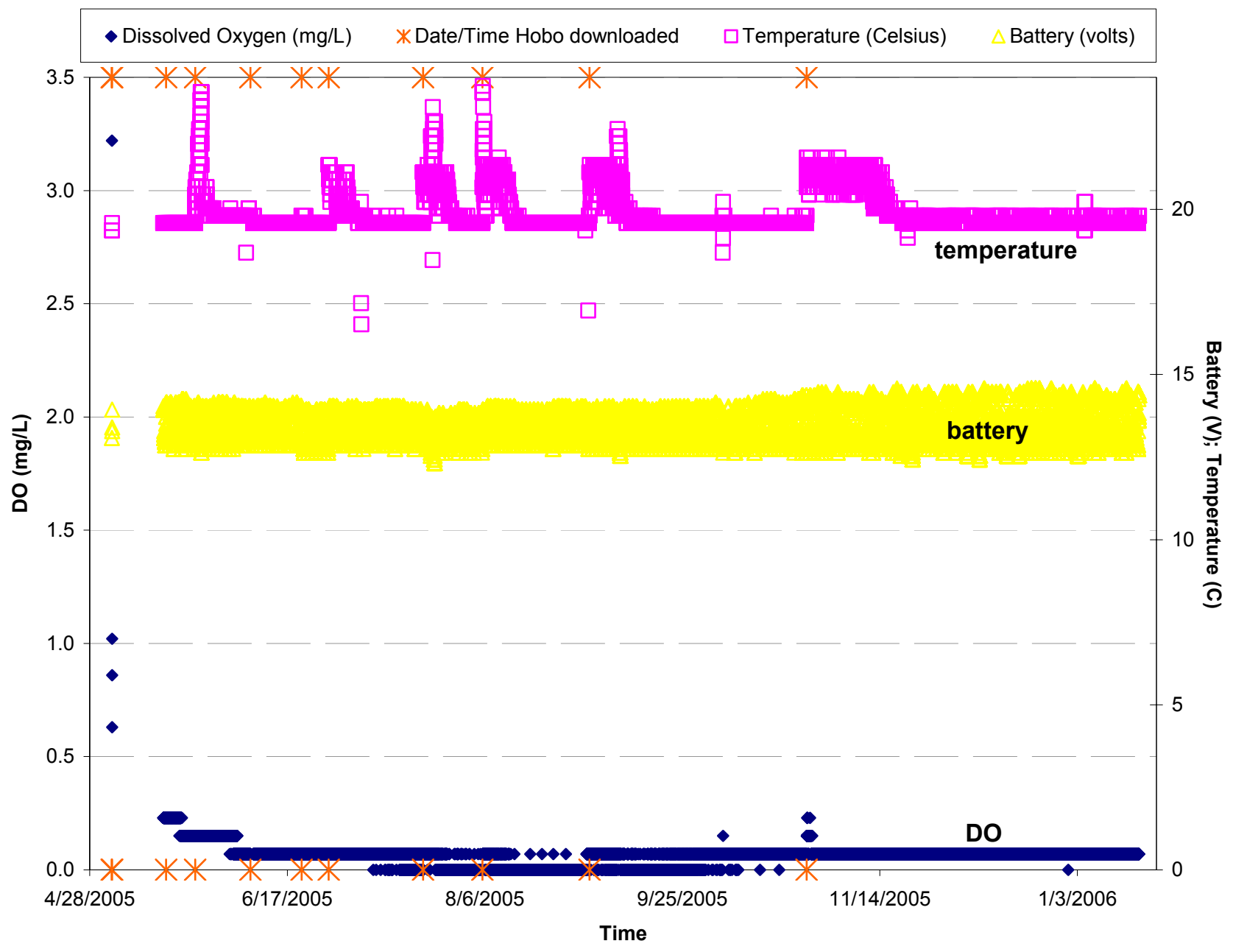


Figure 21. Calibration of the Aanderaa in Air

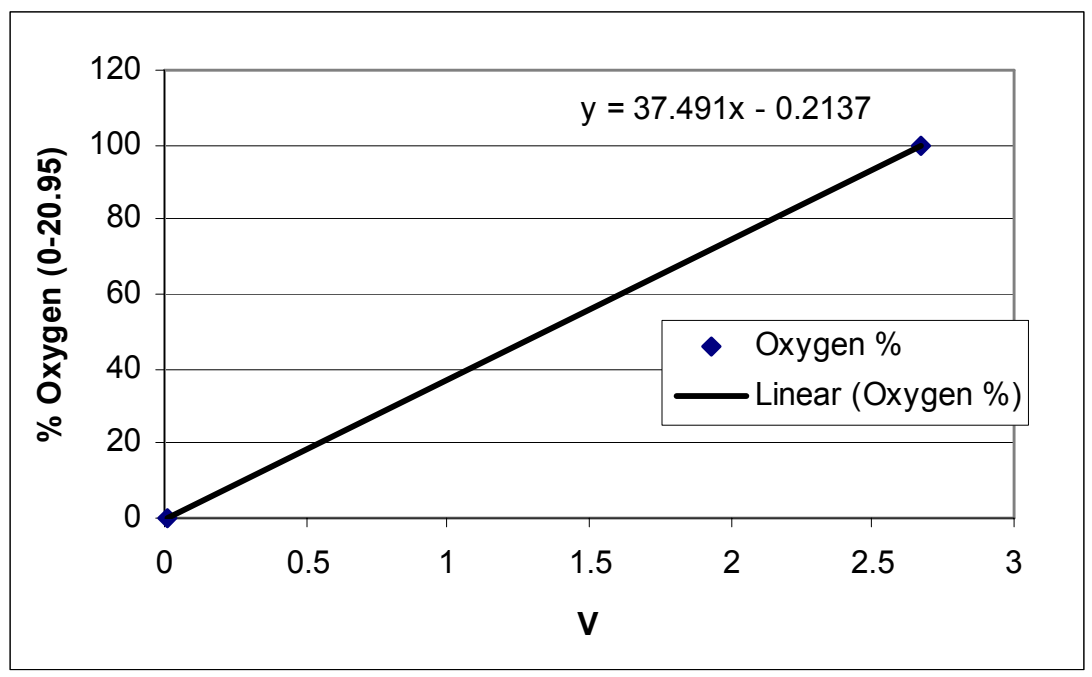

\begin{tabular}{|c|c|c|c|c|}
\hline Temp C & $\begin{array}{c}\text { Pressure } \\
\text { mbar }\end{array}$ & $\begin{array}{c}\text { Humidity } \\
\%\end{array}$ & $\begin{array}{c}\text { Voltage } \\
\text { V }\end{array}$ & $\begin{array}{c}\text { Oxygen } \\
\%\end{array}$ \\
\hline 25.89 & 1006.4 & 100 & 2.673 & 100 \\
\hline 22.60 & 1007.0 & 0 & 0.0057 & 0 \\
\hline
\end{tabular}

Figure 22. Field Site in M Area and Campbell Datalogger
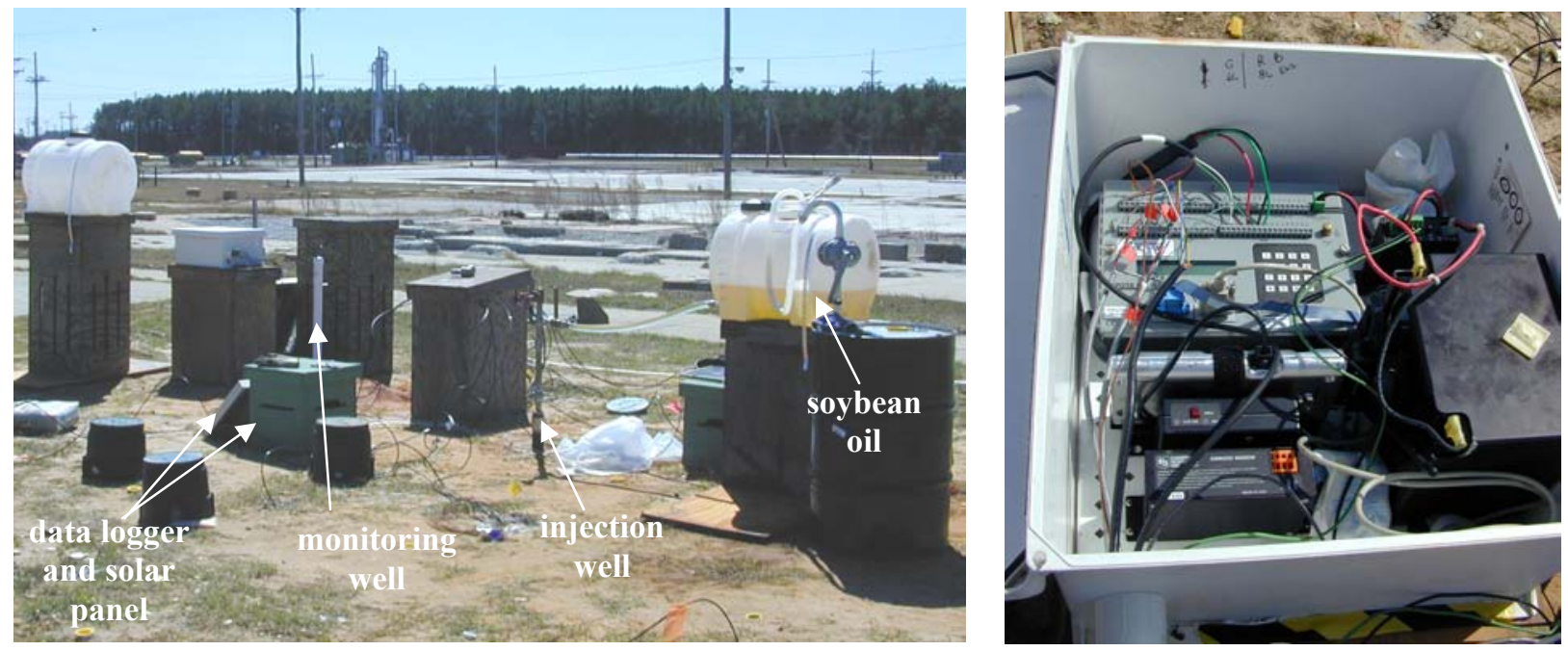